ISSN 0819-2642

ISBN 0734025998

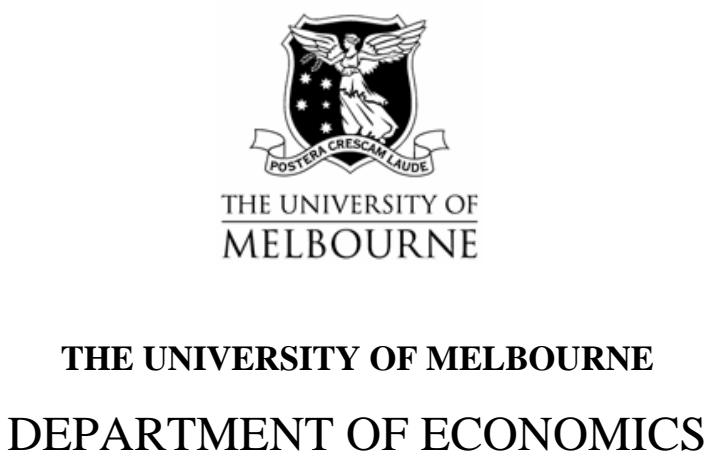

RESEARCH PAPER NUMBER 943

JULY 2005

Do Attitudes Towards Corruption Differ Across Cultures? Experimental Evidence from Australia, India, Indonesia and Singapore

\author{
by \\ Lisa Cameron \\ $\&$ \\ Ananish Chaudhuri \\ \& \\ Nisvan Erkal \\ \& \\ Lata Gangadharan
}

Department of Economics

The University of Melbourne

Melbourne Victoria 3010

Australia. 


\title{
Do Attitudes Towards Corruption Differ Across Cultures? Experimental Evidence from Australia, India, Indonesia and Singapore*
}

\author{
Lisa Cameron, ${ }^{a}$ Ananish Chaudhuri, ${ }^{b}$ Nisvan Erkal, ${ }^{a}$ Lata Gangadharan ${ }^{a}$ \\ ${ }^{a}$ Department of Economics, University of Melbourne, VIC 3010, Australia. \\ (e-mail: \{lcameron, latag, n.erkal\}@unimelb.edu.au) \\ b Department of Economics, University of Auckland, Private Bag 92019, Auckland, \\ New Zealand. (e-mail: a.chaudhuri@auckland.ac.nz)
}

July 2005

\begin{abstract}
This paper examines cultural differences in attitudes towards corruption by analysing individual-decision making in a corrupt experimental environment. Attitudes towards corruption play a critical role in the persistence of corruption. Our experiments differentiate between the incentives to engage in corrupt behaviour and the incentives to punish corrupt behaviour and allow us to explore whether, in environments characterized by lower levels of corruption, there is both a lower propensity to engage in corrupt behaviour and a higher propensity to punish corrupt behaviour. Based on experiments run in Australia (Melbourne), India (Delhi), Indonesia (Jakarta) and Singapore, we find that there is more variation in the propensities to punish corrupt behaviour than in the propensities to engage in corrupt behaviour across cultures. The results reveal that the subjects in India exhibit a higher tolerance towards corruption than the subjects in Australia while the subjects in Indonesia behave similarly to those in Australia. The subjects in Singapore have a higher propensity to engage in corruption than the subjects in Australia. We also vary our experimental design to examine the impact of a more effective punishment system and the effect of the perceived cost of bribery.
\end{abstract}

JEL Classification: C91, D73, O17, K42.

Keywords: Corruption, Experiments, Punishment, Cultural Analysis

\footnotetext{
* Preliminary versions of this paper have circulated under the titles "An Experimental Analysis of Third-Party Response to Corruption," and "Corruption: An Experimental Analysis." We thank Vivi Alatas, Jeff Borland, Tim Cason, Gary Charness, John Creedy, Rachel Croson, Cary Deck, Sisira Jayasuriya, Charlie Plott, Matthew Rabin, seminar participants at the North American Economic Science Association Meetings (2004), the Econometric Society Australasian Meetings (2004), International Meeting of the Economic Science Association (2004), Deakin University and University of South Australia for their valuable comments. We are grateful to the World Bank, Faculty of Economics and Commerce at the University of Melbourne and the University of Auckland for their financial assistance. Lynette de Silva, Syarifah Liza Munira, Daniel Piccinin, Revy Sjahrial and Jonathan Thong have provided excellent research assistance.
} 


\section{Introduction}

Corruption is a pervasive phenomenon. Transparency International finds that of the 133 countries evaluated for its 2003 Corruption Perceptions Index (CPI) "Seven out of ten countries score less than 5 out of a clean score of $10 \ldots$ Nine out of ten developing countries score less than 5 against a clean score of $10 \ldots . .1$ Corruption is a particularly troubling phenomenon in developing countries because of its negative impact on economic growth. It undermines development by weakening the institutional foundation on which economic growth depends (Klitgaard, 1988; Bardhan, 1997). Mauro (1995) shows that countries with higher corruption rates have a lower ratio of total and private investment to GDP, and, consequently, lower economic growth.

Given its large negative impact, much stands to be gained from understanding the causes of corruption and the ways in which it can be reduced. ${ }^{2}$ The aim of this paper is to contribute to our understanding of corruption by analysing individual decision-making in a corrupt experimental environment. We report findings from an experiment designed to explore whether attitudes towards corruption differ across cultures. Attitudes towards corruption play a critical role in the persistence of corruption. ${ }^{3}$ They may differ across cultures as a result of different levels of exposure to corruption. That is, higher levels of exposure to corruption in daily life may promote a tolerance of corruption that is reflected in norms of behaviour. A corrupt environment

\footnotetext{
${ }^{1}$ See http://www.transparency.org/surveys/index.html\#cpi for information on the CPI. Table A1 in the Appendix contains a selective list of country rankings from the 2003 Corruption Perceptions Index (CPI). This Index ranks countries in terms of the degree to which corruption is perceived to exist among politicians and public officials. It reflects the views of analysts and business people around the world, including experts living in the countries evaluated.

2 Previous studies have discussed the importance of deregulation, civil service reform, inter-governmental competition and an effective legal system in reducing corruption. See, for example, Rose-Ackerman (1978). Glaeser and Goldin (2004) discuss the historical factors that may have helped reduce corruption in the United States.

${ }^{3}$ The fact that countries with similar degrees of development may have significantly different levels of corruption suggests that corruption may at least partially be a cultural phenomenon. For instance, Finland, with a 2002 per capita GDP of 26,495 USD, is ranked 1st in the 2003 edition of the CPI while Italy with a 2002 per capita GDP of 25,568 USD is ranked $35^{\text {th }}$. Portugal, with a 2002 per capita GDP of 18,434 USD is ranked $25^{\text {th }}$ while Greece with a 2002 per capita GDP of 18,439 USD is ranked $50^{\text {th }}$.
} 
may make it easier to justify one's own corrupt behaviour. Hence, corruption may gain more acceptance as it becomes more widespread and such acceptance of corruption may contribute to its further spread and sustenance (Dey, 1989).

The set of actions that fall under the rubric of "corrupt acts" is large. We define corruption as a situation where two people can act to increase their own payoff at the expense of a third person, the victim. We assume that the transaction that takes place between the two people is illegal, so the victim is allowed to punish them. However, punishment is costly to the victim. As suggested by Fehr and Gächter (2002) and Bowles and Gintis (2002), such "altruistic" punishment by homo reciprocans, humans who are willing to punish norm violators even when such punishment is costly to the punishers, may be the primary driving force behind sustaining cooperative norms in a variety of social dilemmas.

Several papers in the theoretical literature on corruption focus on the cultural aspects of corruption (e.g., Andvig and Moene, 1990; Hauk and Saez-Marti, 2002; Lui, 1986; Sah, 1988; Tirole, 1996). However, empirical support for the cultural aspects of corruption is harder to find due to the aggregate nature of most of the existing data on corruption. ${ }^{4}$ Experimental methodology provides us with a unique opportunity to explore how individuals' attitudes towards corruption differ across cultures.

We assume individuals' attitudes towards corruption are shaped by the social, political, legal and economic systems of the countries they live in as well as their everyday experiences of corruption. We refer to all these elements that shape individuals' attitudes as culture. It is important to define what we mean by attitudes towards corruption. We differentiate between the incentive to engage in a corrupt act from which one reaps benefits and the incentive to incur a

\footnotetext{
${ }^{4}$ Treisman (2000) is one empirical study that uses country level data to analyse the cultural foundations of corruption.
} 
cost to punish a corrupt act which decreases one's payoff. This distinction enables us to examine whether individuals' behaviour differ depending on whether they directly benefit from a corrupt act.

Our goal is to explore whether, in environments characterized by lower levels of corruption, there is both a lower propensity to engage in corrupt behaviour and a higher propensity to punish corrupt behaviour. We report findings from experiments conducted in four countries: Australia (Melbourne), India (Delhi), Indonesia (Jakarta), and Singapore. We have chosen to run our experiments in two countries that are consistently ranked among the least corrupt countries in the world (Australia and Singapore, with scores of 8.8 and 9.4 out of 10 respectively) and two countries that are consistently ranked among the most corrupt (India and Indonesia, with scores of 2.8 and 1.9 respectively). ${ }^{5}$ Moreover, Singapore and Indonesia are included in our sample because both have experienced relatively recent changes in institutional structure, albeit of a very different nature. In Singapore, the approach to eradicating corruption has been strictly top-down. The government has imposed and strongly enforced strict anticorruption laws and has been successful in reducing corruption in a relatively short time period (approximately 40 years). Indonesia still has a high level of corruption, but it has recently become a democracy (in 1998) and is seeing the emergence of a free and independent press. These institutional changes have been accompanied by a groundswell of public opinion condemning corruption.

Our results indicate that there is a larger variation in the propensities to punish corrupt behaviour than in the propensities to engage in corrupt behaviour across countries. Specifically, there are no differences in the propensities to engage in corrupt behaviour, but a significant difference in the propensities to punish corrupt behaviour between Australia and India. Hence,

\footnotetext{
${ }^{5}$ See Table A1.
} 
the subjects in Australia, a country characterized by a low level of corruption, tend to be more critical of corrupt behaviour that they observe in others than they are of corrupt behaviour of which they are the direct beneficiary. When we analyse behaviour in the two countries with recent institutional changes, Indonesia and Singapore, we surprisingly find results different from what is implied by the reported levels of corruption in these countries. While the subjects in Indonesia have the same attitudes towards corruption as the subjects in Australia, the subjects in Singapore exhibit a higher tolerance towards corruption than the subjects in Australia.

In addition to examining differences in attitudes towards corruption across cultures, we varied our experimental treatment to examine whether the propensity to engage in corrupt behaviour varies with the effectiveness of the existing legal system and the cost of corruption. We assume that a more effective punishment system allows the victim to mete out a larger punishment and conducted experiments with both a low and high punishment regime. We varied the cost of corruption by conducting one treatment with a welfare-enhancing bribe, where the total payoff gains from the bribe exceed the total payoff loss, and another treatment with a welfare-reducing bribe, where the reverse is true.

The rest of the paper is organized as follows. Section 2 describes the related experimental literature. Section 3 explains the experimental design and procedure. Section 4 presents the results and discusses their implications. Section 5 concludes.

\section{Previous Experimental Literature on Corruption and Punishment}

The experimental literature examining corruption is scarce. Abbink, Irlenbusch and Renner (2002) model corruption as a variant of the two-person trust and reciprocation game, where the participants play the role of a briber or a public official. They find that the fact that a corrupt act has a negative externality on the other participants does not result in a lower level of 
corruption. However, the introduction of a threat of high penalties when discovered significantly reduces corruption. Abbink, Irlenbusch and Renner (2000) differentiate between positive and negative reciprocity in their trust and reciprocation game and find that subjects engage in negative reciprocity more often. Barr, Lindelow and Serneels (2004) study the embezzlement of public resources using nursing students in Ethiopia. They find that corruption is less likely to take place when service providers earn more income, and when the risk of being caught and sanctioned is high. Frank and Schulze (2000) find that economics students are significantly more corrupt than others. They show that this is due to a process of self-selection rather than indoctrination and argue that it is the more self-interested students who choose to study economics.

Our paper differs from these papers in two main ways. First, to the best of our knowledge, our study is the first one to focus on how individual attitudes towards corruption differ across cultures. In doing so, we contribute to a growing experimental literature on crosscultural comparisons of behaviour. ${ }^{6}$ Second, as discussed above and unlike previous studies, we are able to examine both the incentives to engage in corruption and the incentives to punish corrupt behaviour. The previous studies on corruption model punishment as an exogenous lottery. In our paper, punishment is endogenous and takes place if the victim decides to incur the cost to punish.

The way we model punishment has some similarities with the literature on the impact of sanctions (formal or informal) on individual behaviour. In recent years, there has been a growing interest in this area. Fehr and Gachter (2000) show that the cooperators in a public goods game

\footnotetext{
${ }^{6}$ See, for example, Carpenter and Cardenas (2004), Croson and Buchan (1999), Roth et al. (1991) and Henrich et al. (2004).
} 
display a widespread willingness to punish the free riders. ${ }^{7}$ Their results reveal that in the presence of formal monetary punishment opportunities, there is less free riding in these games. Masclet et al. (2003) find that nonmonetary sanctions can also lead to high cooperation levels. These papers examine the impact of punishment in a game where the punishment is meted out by those who are directly affected by others' free riding. Fehr and Fischbacher (2004) and Carpenter and Matthews (2004) show that punishment by a third party, whose payoffs are not affected by the norm violation, is another way of deterring non-cooperation. ${ }^{8}$

\section{Experimental Methodology}

\subsection{Design}

We are interested in examining whether there are differences in the propensities to engage in and the propensities to punish corrupt behaviour across cultures with different experiences of corruption. To this end, we have designed a three-person, sequential-move game that focuses on a common bribery problem. The first player is a firm who has the option of initiating a corrupt act by offering a bribe to a government official in order to increase its own payoff at the expense of society. The second player, whom we call the official, can either reject or accept the bribe. The third player represents society and is called the citizen. This player can respond to the act of corruption by choosing to punish both the firm and the official. The punishment is costly to the citizen, and imposes a monetary sanction on the firm and the official.

Figure 1 contains an extensive-form representation of the game, where all of the payoffs are denoted in experimental dollars. We constrain the amount of the bribe that the firm can offer

\footnotetext{
${ }^{7}$ In a public goods game, each player receives an initial endowment and is asked to contribute a fraction of the endowment to a group account, keeping the remainder. The funds in the group account provide a positive return to each member of the group. Though it is in the group's interest to maximise the contributions, the dominant strategy for each player is to contribute zero to the group account (i.e., to free ride).

${ }^{8}$ Bowles and Gintis (2002), Fehr, Fischbacher and Gachter (2002), and Casari and Plott (2003) provide further evidence on how punishment can have an impact on behaviour and social norms.
} 
to $\mathrm{B} \in[4,8]$. It costs the firm two experimental dollars to offer a bribe and the firm incurs this cost regardless of whether the bribe is accepted. If a bribe is offered, then the official decides whether to accept it. If the official accepts the bribe (which automatically implies favorable treatment of the firm), then the payoffs of the firm and the official increase by $3 \mathrm{~B}$ while the payoff of the citizen decreases. Hence, the net benefit to the firm from paying the bribe is $3 \mathrm{~B}-2$. This may, for example, be the benefit the firm gets from avoiding a regulation. As far as the official is concerned, we assume that the official's payoff increases by $3 \mathrm{~B}$ even though the amount of bribe paid by the firm is B. This is due to a difference in the marginal utility of income. Since the income earned in the public service is likely to be lower than that earned in private firms, the same amount of money can be assumed to have a lower marginal utility value to the firm than to the official. Abbink, Irlenbusch and Renner (2002) make a similar assumption in their paper. As in their paper, this multiplier also has the additional advantage of helping us prevent negative total payoffs.

If a bribe has been offered and accepted, the citizen, who moves last after observing the choices made by the firm and the official, is given a chance to punish the firm and the official for the corrupt transaction. The citizen can choose an amount $\mathrm{P}$ in punishment. Such punishment is costly for the citizen and reduces the citizen's payoff by the amount of the punishment, P. However, if the citizen chooses to punish, then the payoffs of the firm and the official are reduced by three times the amount of the punishment chosen by the citizen.

In the subgame perfect equilibrium of this game, a payoff-maximizing citizen does not punish. Knowing this, the official accepts the bribe and the firm offers the bribe. Moreover, the firm offers the maximum amount of bribe it can since its payoff is increasing in the amount it offers. 
We have deliberately chosen to conduct a one-shot game because in a one-shot game the punishment has no economic benefit to the citizen and so the decision to punish is not affected by the anticipation of possible future economic gains. If we observe any punishment by the citizens, we can infer that it is motivated by either negative reciprocity or moral considerations. Hence, with a one-shot game, a comparison of the citizens' willingness to punish across different cultures reveals the differences in the tolerance levels for corrupt acts across the different cultures. The citizens who choose to punish in a one-shot game would have even more incentives to punish in a multi-period game since by doing so, they can deter corruption and decrease the harm they suffer.

The one-shot nature of the game also helps us avoid the issues associated with repeated games, such as signalling, reputation formation and serial correlation in decisions. Hence, each subject in our database participated in the experiment only once and played only one role. ${ }^{9}$ The subjects playing the three roles were grouped anonymously in the experiment to avoid conscious or unconscious signalling.

\subsection{Procedure}

Each experiment lasted about an hour. At the end of each session, the payoffs were converted into cash using an appropriate conversion rate, taking into consideration purchasing power parity across the countries where the experiment was conducted. ${ }^{10}$ To guarantee parity in

\footnotetext{
${ }^{9}$ One standard response in cases such as these is to have random re-matching of subjects. Kandori (1992) states that it is not clear whether random re-matchings do actually succeed in eliminating supergame effects. However, Duffy and Ochs (2005) consider an experiment with an indefinitely repeated 2-player prisoner's dilemma game and find that contrary to Kandori's theoretical conjecture, a cooperative norm does not emerge in the treatments where players are matched randomly. In the current paper we decided to adopt a conservative stance and have players participate in pure one-shot games to avoid any repeated game effects.

${ }^{10}$ The conversion rates in each country were based on 1) the standard hourly wage paid for a student research assistant in each country, and 2) a typical basket of goods bought by students in each country. This is similar to the procedure used by other researchers who have conducted cross-cultural studies (e.g., Carpenter and Cardenas, 2004 and Cardenas and Carpenter, 2005).
} 
the payoffs to the different type of players (firm, official and citizen), we used a different conversion rate for each type. ${ }^{11}$ These conversion rates were public information.

The experiments were run at the University of Melbourne, the Delhi School of Economics, the University of Indonesia, and the National University of Singapore using third year undergraduate or postgraduate students. In order to minimize the experimenter effects, we made sure that one of the authors (the same one) was present in all the countries where we ran the experiment. ${ }^{12}$ All the sessions were run as non-computerized experiments. 1935 subjects participated once and only once as a firm, an official, or a citizen.

Given the large number of subjects involved and the non-computerized nature of the experiments, the logistics of running the sessions posed a challenge. At the beginning of each session subjects were asked to come to a large lecture theatre. Each session consisted of at least 30 subjects. These subjects, on entering the room, were randomly designated as either firms, officials or citizens. Each group was located far apart from the others in a recognizable cluster. Thus, each group could see the members of the other groups, but individual subjects were unaware of which three specific subjects constituted a particular firm-official-citizen trio.

At the beginning of each session, each subject received a copy of the game's instructions, which were then read out loud to them. They were also given a number of examples explaining how the payoffs would be calculated for specific bribe and punishment amounts. Then, the subjects playing the role of a firm were asked to decide whether or not to offer a bribe. If they chose to offer a bribe, they also had to choose an amount. The record sheets with the bribe amounts were then collected and distributed by the experimenter to the corresponding officials.

\footnotetext{
${ }^{11}$ In Australia, the conversion rates were 3 experimental currency $=1$ real currency for the firms, 2 experimental currency $=1$ real currency for the officials and 1.5 experimental currency $=1$ real currency for the citizens. Each subject made on average AU\$20. This amount is approximately equivalent to US\$15. In India subjects were paid an average of US\$11, in Singapore US\$13, and in Indonesia US\$9.

${ }^{12}$ Roth et al. (1991) and Cardenas and Carpenter (2005) discuss the methodological issues arising in multi-site experiments.
} 
After the officials made their decisions, the corresponding citizens were informed about whether a bribe was offered and whether it was accepted. The game ended after the citizens decided whether to punish by choosing a punishment amount. The decisions made by all of the subjects were entered into a spreadsheet which generated their payoffs. The subjects were paid at the end of each session.

All the subjects filled out a demographic survey, which asked them a series of questions on age, gender, income, education stream, employment history, and frequency of exposure to corruption. Those in the role of the citizen were also asked to explain the motivation for their decisions. $^{13}$

We should point out that we deliberately chose to use emotive terms such as "bribe" and "punishment" in the instructions. This is a deviation from the standard practice of using neutral language in economics experiments. However, since our aim was to simulate a real-life corrupt transaction, we used loaded language. As indicated in Harrison and List (2004), "it is not the case that abstract, context-free experiments provide more general findings if the context itself is relevant to the performance of subjects (p. 1022).”

In addition to the 1935 observations that we report in the paper, we have also collected data using a neutral language treatment where we eschewed words such as "bribe" or "punishment." They were replaced by words such as "transfer" and "forego money to reduce others' payoff' respectively. Among the 132 subjects that participated in this treatment, the behaviour was closer to the subgame perfect equilibrium outcome. In particular, the punishment levels were lower in the neutral language sessions suggesting that the subjects participating in the

\footnotetext{
${ }^{13}$ The instruction, record and survey sheets are available from the authors upon request.
} 
loaded language sessions respond to the context given to them. We refer to the results from these data as and when appropriate in footnotes in the rest of the paper. ${ }^{14}$

\subsection{Treatments}

We conducted the following three treatments to examine whether the effectiveness of the punishment regime and the cost of the bribe affect behaviour. Treatment 1 corresponds to the low punishment regime, where we restricted the range of the punishment to $\mathrm{P} \in[2,8]$. Treatment 2 corresponds to the high punishment regime, where we allowed the citizen to choose a punishment level $\mathrm{P} \in[2,12] .{ }^{15}$ Our goal in designing Treatments 1 and 2 was to observe whether a more effective punishment system decreases the incentives to engage in corrupt behaviour and increases the incentives to punish corrupt behaviour. An alternative way of designing a more effective punishment system would be to increase the multiplier on the punishment level chosen by the citizen. However, we chose to increase the punishment options available to the citizens since we were also interested in examining whether the choice set available to the subject affects behaviour. In other words, we wanted to observe whether the availability of higher punishment amounts resulted in an increase in the frequency of subjects who chose a punishment level $\mathrm{P} \in[2,8]$. Such behaviour would indicate that the effectiveness of the system matters.

In both Treatments 1 and 2, the bribe is welfare-enhancing, in that the total payoff gains to the firm and the official exceed the payoff loss to the citizen. In Treatment 3, using a high punishment regime, we considered a welfare-reducing bribe game, where the combined gains to

\footnotetext{
${ }^{14}$ Cooper and Kagel (2003) consider the role of loaded language in signaling games and suggest that the use of a meaningful context might better capture behaviour in field settings than the use of neutral language. However, Abbink and Hennig-Schmidt (2002) find that the use of words like "bribe" do not make a difference in the corruption game that they study.

${ }^{15}$ These values were chosen to guarantee two things. First, we wanted to ensure that no one obtained a negative payoff. Second, we wanted to make sure that the payoffs were not unduly inequitable. Often, if the payoffs are excessively unequal, it leads to confounding changes in behaviour.
} 
the firm and the official are less than the payoff loss to the citizen. Specifically, in the welfareenhancing bribe game, each dollar offered in bribe, if accepted, reduces the payoff to the citizen by $\$ 1$ whereas in the welfare-reducing bribe game, it reduces the payoff to the citizen by $\$ 7$. Figures 1 and 2 describe the associated payoffs to the three players in the welfare-enhancing bribe game and the welfare-reducing bribe game respectively. ${ }^{16}$ These two game structures are designed to represent the concepts of beneficial corruption, where bribery is assumed to be good or essential for economic growth, and detrimental corruption, where bribery is assumed to inhibit economic progress.

The distinction between welfare-enhancing and welfare-reducing corruption is one that is frequently made in the literature. ${ }^{17}$ As an example, consider the scenario where a firm would like to import certain goods, but it needs to obtain a license to do so. In order to acquire the license, the firm has to bribe a government official. Here, although undoubtedly corrupt, the immediate social cost of this action is possibly not very high. In contrast, consider the case where the same firm manages to bribe its way out of complying with some environmental regulations and dumps toxic waste into the groundwater. Our goal in running Treatments 2 and 3 is to explore whether the tendency to engage in and punish corrupt behaviour is different in the latter case, where the cost of bribery is potentially far greater.

Our approach to the welfare implications of bribery is different from the approach of Abbink, Irlenbusch and Renner (2002), who examine whether behaviour changes when the corrupt act imposes a negative externality (in the form of a fixed monetary damage) on the other participants in the experiment. In contrast, we explore the welfare implications of bribery by

\footnotetext{
${ }^{16}$ The games are welfare-enhancing and welfare-reducing both before and after taking into account the relevant conversion rates.

${ }^{17}$ See, for example, Ali and Isse (2003), Kaufman and Wei (1999), Bardhan (1997), Nas, Price and Weber (1986), and Lui (1986).
} 
varying the harm it imposes on the victim. We analyse how sensitive the citizen's behaviour is to the level of harm they experience rather than the level of harm others experience.

A change in the cost of bribery may have the following effects on subject behaviour. When the bribe is welfare-reducing, the subjects may think that it is less justified. Moreover, as the harm imposed on the citizen increases, the citizen may choose to punish due to feelings of negative reciprocity. Both of these effects would result in lower bribe amounts and higher punishment amounts being chosen when the bribe is welfare-reducing. Alternatively, if the harm imposed on the citizen is sufficiently large, the citizen may not want to punish and decrease his/her payoff by even more. As a result, punishment may occur less frequently, and if the firms and officials anticipate this, they may act more corruptly. Hence, whether we observe higher levels of bribery and punishment in Treatment 3 than in Treatment 2 depends on the relative magnitude of these effects.

\section{Results}

\subsection{Overview of the results}

Table 1 summarizes the data we collected in terms of the treatments we ran at each location and the number of subjects involved in each treatment. ${ }^{18}$ Figure 3 provides a broad overview of our findings. Overall 1935 subjects participated in 645 plays of the game across all treatments since it takes three players (a firm, an official and a citizen) to generate one play of the game. Note that in the subgame perfect equilibrium of the game, the firm offers the maximum amount of bribe possible, the official accepts, and the citizen does not punish. As can be seen from Figure 3, in 555 out of $645(86.0 \%)$ plays of the game a bribe was offered by the

\footnotetext{
${ }^{18}$ We do not have data for all three treatments in India, Indonesia and Singapore. Given the resource constraints we faced, we allocated the treatments such that we could compare behaviour in the different treatments using data collected from at least one low-corruption and one high-corruption country.
} 
firm. The average amount of the bribe for those who chose to bribe was $\$ 7.50$ (out of a range of 4 to 8$) .482$ out of 555 (86.9\%) officials who received a bribe chose to accept it. Both the firm's and official's behaviour is more or less in accordance with the theoretical predictions. However, the citizens' behaviour deviates sharply from the theoretical prediction. 238 out of $482(49.4 \%)$ citizens who were harmed by the bribe chose to incur a pecuniary cost in order to punish the firm and the official for their actions. The remaining 244 citizens (50.6\%) chose not to punish. ${ }^{19}$

In the next two subsections, we present our findings in more detail. We first report the results on the cultural effects in Section 4.2. We then consider the impact of the punishment regime and the cost of bribery on individual behaviour in Section 4.3.

\subsection{Comparing Behaviour in Australia, India, Indonesia and Singapore}

Since we are interested in both the propensity to initiate and accept bribes, and the propensity to punish bribery, we start by examining the decisions of the firms and the officials across the four countries in Section 4.2.1. Then we turn to the decision of the citizens in Section 4.2.2. In Section 4.2.3 we discuss the implications of the results we present in the previous two subsections.

The reported results are based on t-tests and multivariate regression analysis. We also conducted non-parametric rank sum tests of differences in distribution. Unless noted in the text, the results were the same as the ones in the reported t-tests. ${ }^{20}$ We estimated binary probit models for the bribe, acceptance and punishment rates, and ordinary least square models for the bribe

\footnotetext{
${ }^{19}$ The bribe and acceptance rates are higher in the neutral language games than they are in the loaded language games. There were 44 plays of the neutral language game. The bribe was offered in $39(88 \%)$ of the cases (compared to $86 \%$ in the loaded language game). This bribe was accepted in $38(97 \%)$ out of 39 of the cases (compared to $87 \%$ in the loaded language game). The most significant difference was in the punishment rates. Out of the 38 citizens in the neutral language game who were in a position to punish, 14 of them (37\%) chose to punish (compared to $49 \%$ in the loaded language game).

${ }^{20}$ The rank sum test results are available from the authors on request.
} 
and punishment amounts. The regression results control for several aspects of the subjects' backgrounds based on the information collected in the surveys.

\subsubsection{Bribe and Acceptance Behaviour}

We start by comparing the results from Australia and India, where we conducted the low punishment treatment (Treatment 1). As discussed above, India has a significantly higher corruption level than Australia and we are interested in examining whether this difference is reflected in the bribe and acceptance behaviour in the two countries. Figure $4 \mathrm{~A}$ compares the bribe behaviour of the Australian and Indian subject pools. Table 2, Panel (i) summarises the behaviour of the three types of players and the results of t-tests for statistically significant differences in the means. We find no statistically significant difference in the rates at which a bribe was offered $(\mathrm{p}=0.63)$. A bribe was offered in India in $94 \%$ of the cases while it was offered in Australia in $96 \%$ of the cases. Similarly, we find no significant differences in the bribe acceptance rates. The bribe was accepted in $90 \%$ of the cases in India and in $91 \%$ of the cases in Australia. The only significant difference we find between Australia and India is in the bribe amounts. The bribe amount offered in India is slightly lower than that offered in Australia (the average amounts were $\$ 7.37$ and $\$ 7.70$ respectively). This difference is statistically significant according to a test of difference of means $(\mathrm{p}=0.03)$.

These results are consistent with the regression results presented in Table 4, Panel A, where we pool all of the data for all of the treatments across all of the countries, and in Table 4, Panel B, where we compare behaviour in Australia and India for Treatment 1. Columns 1-6 in Table 4 present the results for the bribe rate, acceptance rate and bribe amount respectively. ${ }^{21}$ Pooling the data allows us to compare the behaviour across the four countries while controlling

\footnotetext{
${ }^{21} \mathrm{We}$ also estimated ordered probit models for positive bribe amounts. These recognise that the dependent variable is not continuous. The results were very similar to the reported results from the estimation of ordinary least squares models.
} 
for treatment effects as well as other variables not accounted for in the t-tests, such as gender, field of study (whether it is economics), and the percentage of each Australian subject's life that has been spent outside of Australia. ${ }^{22}$ Of the variables we collected information on, these were found to be the only ones that were consistently significant determinants of subject behaviour. ${ }^{23}$ In the regressions for the officials' behaviour, we also controlled for the bribe amount.

In Australia, Indonesia and Singapore we conducted both the welfare-enhancing and welfare-reducing treatments (Treatments 2 and 3). Figure 4B pools the results from these treatments and compares them across the three countries. ${ }^{24}$ Given the high level of corruption that exists in Indonesia, as in the case of India, we expected the Indonesian subjects to display a relatively high tolerance of corruption. However, the graphs in Figure $4 \mathrm{~B}$ are notable in that there is no striking difference between the firms' behaviour in Australia and Indonesia. Table 2, Panels (ii)-(vii) compare the means of behaviour across the Australian, Indonesian and Singaporean subjects within each treatment. The summary statistics confirm our observations from the graphs. Specifically, the propensities to bribe, the bribe amounts, and the propensities to accept are all similar in Australia and Indonesia. The point estimates are more similar for Treatment 2 than for Treatment 3. In Treatment 3, they suggest a lower tolerance of corruption in Indonesia, where a smaller percentage of the subjects offered $(78 \%$ in Indonesia versus $88 \%$ in Australia) and accepted bribes (79\% in Indonesia versus $89 \%$ in Australia). However, the differences are not statistically significant ( $p=0.13$ in both cases). The regression results presented in Table 4, Panel A also indicate that the Indonesian subjects do not differ from the

\footnotetext{
${ }^{22}$ The last variable controls for the high number of foreign students that study in Australian universities. The majority of these students come from Asia. We find this variable to be insignificant in explaining behaviour in most of the regressions. This is possibly because those who choose to study in Australia are more westernised than their counterparts and/or quickly absorb the social norms of the new environment.

${ }^{23}$ We collected information on age, gender, field of study, work experience, income, exposure to corruption and time spent in developed countries.

${ }^{24}$ We discuss how subject behaviour varies across welfare-enhancing and welfare-reducing treatments in Section 4.3.2.
} 
Australian subjects in terms of their propensities to offer and accept bribes. The bribe amount is marginally smaller in Indonesia as compared with that in Australia (significant at the $10 \%$ level).

The graphs in Figure 4B present the bribe behaviour in Australia and Singapore. The results reported in Table 2, Panels (iv) and (v) show that the bribe rate is lower in Australia in Treatment 2 (79\% versus $86 \%)$ while it is lower in Singapore in Treatment 3 (88\% versus $84 \%)$. In both treatments the acceptance rates of the officials is higher in Singapore than in Australia (81\% versus $89 \%$ in Treatment 2 and $89 \%$ versus $96 \%$ in Treatment 3 ). None of these differences are statistically significant, which is in accordance with our expectations since Singapore is consistently ranked as a very low-corruption country.

However, once we turn to the regression results presented in Table 4, Panel A, we find that the difference between Australia and Singapore becomes more significant. The Singaporean subjects have a higher probability of offering bribes than the Australian subjects (significant at the $5 \%$ level). They are also more likely to accept bribes as compared to the Australian subjects (significant at the $10 \%$ level). Panels $\mathrm{C}$ and $\mathrm{D}$ of Table 4 show that this result is driven by behaviour in Treatment 2.

A comparison of the Indonesian and Singaporean subject behaviour shows that both the bribe and acceptance rates are also higher in Singapore than in Indonesia. Although the differences in the bribe rates are not statistically significant, the differences in the acceptance rates are statistically significant in both Treatments 2 and $3(p=0.10$ and $p=0.01$ respectively). This is also confirmed in the regression results presented in Panels E and F of Table 4, where dummies for Indonesia and Australia are included and Singapore is taken to be the reference dummy.

In summary, when we compare the propensities to offer and accept bribes across the four locations, we find that the Australian, Indian and Indonesian subjects display quite similar 
behaviour while the Singaporean subjects seem to behave differently. We discuss the implications of these results in Section 4.2.3 after we present the results on the punishment behaviour.

The coefficients on the other control variables in the regressions show that the subjects who study economics have a higher probability of accepting bribes and a lower probability of punishing corruption. The Australian subjects' probability of offering a bribe increases with the time they have spent outside of Australia. As far as gender is concerned, the probability of offering a bribe is higher for men than for women (significant at the $10 \%$ level). Men were also more likely to accept bribes although this difference is not significant. ${ }^{25}$

\subsubsection{Punishment Behaviour}

We find larger differences between the four locations when we consider the punishment behaviour. Figure 5A displays the punishment patterns in Australia and India. As shown in Table 2, Panel (i), only $24 \%$ of citizens chose to punish in India compared to $53 \%$ in Australia (p = 0.0001). The amounts that these citizens handed out in punishment were also significantly different. In Australia, among the subjects who chose to punish, the average punishment amount was $\$ 5.40$ while in India it was $\$ 3.71(p=0.01)$. These results are consistent with the pooled regression results presented in Table 4, Panels A and B, columns 7-10. We estimated probit models for the punishment rates and ordinary least squares models for the punishment amounts given out by the citizens for positive punishment amounts, controlling for the treatments, the bribe amount, and other variables as discussed in the previous subsection. ${ }^{26}$ The regression

\footnotetext{
${ }^{25}$ Recent empirical papers that have analyzed the link between gender and the level of corruption find that there exist systematic gender differences in attitudes towards corrupt behaviour. For example, Swamy et al. (2001) and Dollar et al. (2001) suggest, on the basis of survey evidence, that women are less tolerant of corruption. We report our findings from experiments in Alatas et al. (2005).

${ }^{26}$ Similar to the regressions on bribe amounts, we also estimated ordered probits for positive punishment amounts, which recognise that the dependent variable is not continuous. The results are very similar to the reported ordinary least squares results.
} 
results show that the Indian subjects are 25 percentage points less likely to punish as compared to the Australian subjects.

The punishment behaviour in Indonesia (Figure 5B) suggests a lower tolerance of corruption as compared with Australia. As shown in Table 2, Panels (ii) and (iii), a greater percentage of Indonesians chose to punish under both of the treatments $(73 \%$ versus $62 \%$ in Treatment 2 and $60 \%$ versus $42 \%$ in Treatment 3). However, as shown both in Table 2, Panels (ii) and (iii) and in Table 4, Panels C and D, only the difference observed in Treatment 3 is significant (at the $10 \%$ level). The punishment amounts do not differ significantly.

The Singaporean subjects punished less frequently as compared to the Australian and Indonesian subjects in Treatment 2 (44\% in Singapore versus $62 \%$ in Australia and $73 \%$ in Indonesia). However, in Treatment 3, there are no significant differences in the punishment rates we observe in the three locations. Punishment amounts do not differ significantly in either treatment in these pairwise country comparisons. These treatment-specific differences are confirmed by the separate regressions we conducted for Treatments 2 and 3 . The results reported in Table 4, Panels C and D show that the subjects in Singapore in Treatment 2 punished at a lower rate as compared to the Australian subjects. This difference is significant at the $10 \%$ level. In Treatment 3, they punish at a higher rate as compared to the corresponding Australian treatment, but this difference is not significant.

When we pool the treatments together (Table 4, Panel A), we find that there are no differences between the Australian and Singaporean subjects. This is because the coefficient on the Singapore dummy averages the differences between the two countries in the punishment rate across the two treatments. However, we find that the Singaporean subjects are 17 percentage points less likely to punish than the Indonesian subjects ( $\mathrm{p}$-value $=0.03$ ), and 20 percentage points more likely to punish than the Indian subjects ( $p$-value $=0.05$ ). The largest difference is 
found between the punishment behaviour of the Indian and Indonesian subjects. The Indonesian subjects are 35 percentage points more likely to punish than the Indian subjects and this difference is strongly statistically significant (p-value $=0.001) .{ }^{27}$

In summary, when we compare the punishment behaviour in the four locations, we find that the Indian subjects display dramatically different behaviour. The Australian and Indonesian subjects behave in similar ways while the Singaporean subjects punish less than the Australian (only in Treatment 2) and Indonesian subjects and more than the Indian subjects.

The regression results also reveal that the students majoring in economics have a significantly lower probability of punishing. Although men have a lower probability of punishing, the gender difference is not statistically significant. However, of the subjects who punish, men punish by higher amounts than women (significant at the $10 \%$ level).

\subsubsection{Insights on Attitudes Towards Corruption Across Cultures}

The results above indicate that the propensities to engage in corrupt behaviour seem to be more similar across the four cultures we have considered than the propensities to condemn corrupt behaviour. Specifically, the Indian subjects are, in general, less willing to impose sanctions on others than the Australian subjects. However, when it comes to engaging in corrupt behaviour, the two samples are quite similar. This finding suggests that people are more ready to sanction behaviour socially regarded as immoral when they see it in others. That we find strong differences in punishment behaviour between the citizen subjects in Australia and the citizen subjects in India supports our conjecture that the Indian citizen subjects may be more tolerant of corruption than their Australian counterparts as a result of the greater prevalence of corruption in India. This bolsters the contention that prevailing social norms might be a significant

\footnotetext{
${ }^{27}$ These findings are from an unreported regression equivalent to that in Table 4, Panel A, but with dummies for India, Singapore and Australia (omitting the Indonesian dummy), and with dummies for India, Indonesia and Australia (omitting the Singapore dummy).
} 
contributory factor in the sustenance of corruption. Corruption flourishes in India because it is commonplace and looks "normal" and is routinely tolerated by the citizenry.

Our findings in Indonesia and Singapore are quite surprising. We find that subject behaviour in Indonesia is quite similar to that in Australia and contrasts with what one would expect based on the reported level of corruption in Indonesia. We conjecture that this may be due to the type of corruption that exists in Indonesia and the recent institutional changes that have occurred in this country. As discussed in Bardhan (1997), corruption in Indonesia has traditionally been more centralized (controlled largely by the first family and the top military leadership in cahoots with the ethnic Chinese-run conglomerates) while corruption in India is more fragmented (p. 1325). Since the introduction of democracy in Indonesia in 1998 and the relaxation of media restrictions, corruption has received a lot more negative media attention. ${ }^{28}$ There have been several attempts (some successful) to prosecute high profile cronies of the previous government who were engaged in corruption to the scale of billions of dollars. Although there is no doubt that corruption remains high in Indonesia, such open discussion and media disapproval have made the existing corruption in the political system more visible to the rest of society and have allowed for widespread public condemnation. Our results suggest that attitudes towards corruption may have consequently hardened in Indonesia and that the tolerance of corruption in Indonesia may currently be below that in India and comparable to that in Australia. ${ }^{29,30}$

\footnotetext{
${ }^{28}$ That corruption receives more attention in Indonesia than in India is borne out by the percentage of newspaper articles that are devoted to the topic. In the time period April to June 2004, approximately 2 per cent of the total number of articles in Times of India relate to domestic corruption. In Indonesia nearly 9 percent of the articles in The Jakarta Post discussed corruption issues during this same time period. As a proportion of the number of articles on political issues, nearly 5 percent in India were on corruption as compared to 11 percent in Indonesia. The methodology we used to calculate these numbers is similar to the one used in Glaeser and Goldin (2004).

${ }^{29}$ Our conjecture is supported by Brunetti and Weder (2003). In a study that involves a large cross-section of countries, they find evidence of a significant negative relationship between press freedom and corruption. Gentzkow, Glaeser and Goldin (2004) also discuss how the rise of the informative press may have been one of the reasons why corruption declined in the US.
} 
To gain some insight into whether the subjects' reasons for punishing differ across the four locations, we asked the citizens why they chose to punish/not to punish in the surveys given to them after they completed the experiment. Table 5 shows our categorization of their responses. ${ }^{31}$ Of the citizens who got a chance to punish, more citizens in Indonesia stated that their intention in punishing is to reduce corruption $(20 \%$ in Indonesia versus $8 \%$ in India, $8 \%$ in Singapore, and $18 \%$ in Australia). More also cite moral considerations as a reason for punishing (39\% in Indonesia versus $14 \%$ in India, $20 \%$ in Singapore, and 32\% in Australia). That corruption is still a serious problem in Indonesia can be seen in the reasons subjects give for not punishing. Of those who chose not to punish, a larger proportion in Indonesia claim that in the environment in which they operate, it is necessary to bribe $(12 \%$ in Indonesia versus $0 \%$ in India, $0 \%$ in Singapore and $4 \%$ in Australia) and that it is difficult to change the system and so easier to be corrupt (48\% in Indonesia as compared to $21 \%$ in India, $18 \%$ in Singapore and $11 \%$ in Australia). The aversion to corruption that is evident in the Indonesian data can tentatively be taken as hopeful in terms of increasing the probability of pressure for and the success of future corruption eradication programs.

The results for Singapore indicate that the subjects there were more likely to engage in corrupt behaviour than the subjects in the other three countries. The punishment rates in Singapore are higher than those in India but lower than those in Australia. The differences between Australia and Singapore are striking given that Singapore consistently ranks as one of

\footnotetext{
${ }^{30}$ India is of course a functioning democracy with a free press, but the relatively smaller scale of high-level corruption in India has not galvanized society to forcefully oppose corruption. Further, corruption was not a major issue at the time when democracy was introduced in India. In contrast, corruption was one of the major causes of the downfall of President Suharto and the advent of democracy in Indonesia.

${ }^{31} \mathrm{We}$ categorized the stated reasons for punishment into four groups: moral responsibility, reduction of corruption, fairness, and negative reciprocity. Similarly, the reasons for not punishing were categorized into three groups depending on whether the subject is profit maximizing, believes that it is difficult to change the system, and thinks that the bribe may be necessary. These categories were not mutually exclusive, so the same person may have been counted in more than one category. We chose to create non-exclusive categories because often it was not possible to determine one single reason for the citizens' behaviour from the statements provided in the surveys.
} 
the least corrupt countries in the world. Hence, other things equal, one would expect the attitudes to corruption to be similar in Australia and Singapore. However, half a century ago the level of corruption in Singapore was comparable to that in India and Indonesia. It has successfully eradicated corruption by the imposition of strict and heavily-enforced anti-corruption legislation. Hence, one possible explanation for our results is that although the strict top-down approach in Singapore for the last 40 years has made Singaporeans less tolerant of corruption (e.g., vis-a-vis Indians), the attitudinal change that accompanies such an approach occurs only slowly and so more time is required for the attitudes towards corruption to change even further.

Table 5 shows that the citizen subjects in Singapore, when compared to those in Australia and Indonesia, were driven to a much greater extent by personal considerations rather than moral responsibility or an attempt to reduce corruption while choosing to punish. Only $20 \%$ of those who punished in Singapore reported doing so for reasons of moral responsibility (versus $320 \%$ in Australia, $14 \%$ in India, and $39 \%$ in Indonesia) and only $8 \%$ reported doing so to reduce corruption (versus 18\% in Australia, $8 \%$ in India, and 20\% in Indonesia).

It is important to keep in mind while making cultural comparisons that the experimental sample is from a particular city in a country. Especially in countries as diverse as India and Indonesia, there are many different cultures which are likely to display different attitudes towards corruption. In these countries, we conducted the experiments in the capital cities, Delhi and Jakarta, which can be argued to have a population that is more representative of the country's culture.

\subsection{Impact of the Punishment Regime and Cost of Bribery}

In this section, we discuss how sensitive subject behaviour is to the effectiveness of the punishment regime and the cost of bribery. We start by comparing the results we have from Treatments 1 and 2 in Australia in Section 4.3.1. We then turn to a comparison of the results we 
have from Treatments 2 and 3 in Australia, Indonesia and Singapore in order to analyse the effect of the cost of bribery on behaviour.

\subsubsection{Low versus High Punishment Regimes (Treatment 1 versus Treatment 2)}

By varying the punishment regime, we examine whether the existence of legal institutions which allow citizens to punish those that engage in corrupt behaviour more effectively reduces the prevalence of corruption.

Figure 6 presents graphs of the distribution of the bribe amounts offered by the firms and the punishment amounts chosen by the citizens under each punishment regime in Australia. Panel A(i) in Table 3 presents the means summarising the behaviour of the three types of players and the results of the t-tests for statistically significant differences in means across the different treatments. The results show that when the citizens are given the opportunity to punish the firms and officials more harshly, i.e., when $\mathrm{P} \in[2,12]$ as in Treatment 2 as opposed to $\mathrm{P} \in[2,8]$ as in Treatment 1 , the possibility of a greater punishment affects the firms' behaviour. $96 \%$ of the firms offered a bribe in the low punishment treatment while only $79 \%$ did in the high punishment treatment. This difference is statistically significant $(\mathrm{p}<0.01)$. The actual bribe amounts offered, however, do not differ across the two treatments $(\$ 7.70$ versus $\$ 7.65)$. Thus, those firms who did offer a bribe behaved in a similar manner in both of the treatments, but many more firms seemed to have perceived the threat of punishment by the citizens as being greater in the high punishment regime and, therefore, preferred to refrain from offering a bribe.

The reaction from the government officials is similar. The propensity to accept a bribe is lower when there is the possibility of a more hefty punishment ( $81 \%$ versus $91 \%$ with a p-value of 0.05). These findings for the firms and officials are consistent with the results in Abbink et al. (2002) and Barr et al. (2003). They also observe that imposing higher penalties reduces corrupt behaviour. The citizens' behaviour reveals that the fear of greater punishment is not without a 
basis. Under the high punishment regime more citizens chose to punish (62\% versus $53 \%)$ with the average amount being slightly higher (6.0 versus 5.4) although these differences are not statistically significant. These results are consistent with the regression results presented in Table 6, Panel A, where Treatment 2 is the reference dummy.

In Figure 6B, the distribution of the punishment amounts chosen by the subjects in Treatments 1 and 2 reveals that a larger percentage of subjects chose a punishment level $\mathrm{P} \in$ $[2,7]$ in Treatment 2. For example, of the subjects who got a chance to punish, $14 \%$ of them chose a punishment of $\$ 2$ in Treatment 1 while $20 \%$ of them chose a punishment of $\$ 2$ in Treatment 2. It is also interesting to observe how the percentage of subjects who chose $\mathrm{P}=\$ 8$ differs across the two treatments $(21 \%$ in Treatment 1 versus $0.05 \%$ in Treatment 2$)$. This difference suggests that in Treatment 1 , some of these subjects chose $\$ 8$ because they could not choose a higher amount.

\subsubsection{Welfare-Enhancing versus Welfare-Reducing Bribe Games (Treatment 2 versus}

\section{Treatment 3)}

The final question we address is whether behaviour differs when the bribe is perceived as being harmful, i.e., when the payoff loss to the citizen exceeds the total payoff gain to the firm and the official. As discussed in Section 3.3, one would expect those subjects who are sensitive to the perceived cost of bribery, to offer and accept bribes less frequently and to punish more frequently in Treatment $3 .{ }^{32}$ On the other hand, those citizen subjects who feel impoverished and disempowered as a result of the high cost of bribery may choose to punish less and those firms and officials that expect this may offer and accept bribes more frequently.

\footnotetext{
${ }^{32}$ It was clear from the survey responses that we collected and the questions we received after the experiments that for some of the subjects the purpose of the bribe, i.e., whether it was for a "good" purpose, mattered.
} 
Treatments 2 and 3 were conducted in Australia, Indonesia and Singapore. Figure 6 and Table 3, Panel A(ii) show that subject behaviour in Australia was more in accordance with what one would expect under the second scenario. The frequency with which a bribe was offered was higher in the welfare-reducing game (88\% versus $79 \%)$ although this difference is significant at the $10 \%$ level only. The frequency with which the bribe was accepted was also higher in the welfare-reducing game (89\% versus $81 \%)$ although this difference is not statistically significant. There are no significant differences in the amount of the bribe offered $(\$ 7.57$ in Treatment 3 versus $\$ 7.65$ in Treatment 2).

The citizens had a significantly lower propensity to punish in the welfare-reducing game $(42 \%$ versus $62 \%, p=0.02)$. Hence, when the bribe had a larger negative impact on the payoff of the citizen, relatively more citizens did not want to forego even more money in order to punish the firm and the official. Interestingly, while fewer citizens punished in the welfare-reducing bribe game, those who did punish punished by considerably larger amounts ( $\$ 7.74$ versus $\$ 5.98$, $\mathrm{p}=0.06)$. This suggests that while the larger harm imposed on the citizen by the bribery discouraged some citizens from choosing to punish, those that did punish felt particularly affronted by the corrupt behaviour. They chose to punish by higher amounts either because of a concern for the welfare-reducing aspect of corruption or because of feelings of negative reciprocity. $^{33}$

As shown in Table 3, Panels $\mathrm{B}$ and $\mathrm{C}$, we find no significant differences in the propensities to engage in corrupt behaviour across the two treatments in Indonesia and Singapore. The point estimates show that, unlike in Australia, the bribe rate was higher in the welfare-enhancing treatment than in the welfare-reducing treatment. This indicates that the subjects in these countries were more concerned about the welfare-reducing impact of the bribe.

\footnotetext{
${ }^{33}$ The regression results in Table 6 are consistent with the reported t-statistics.
} 
However, t-tests, Wilcoxon rank sum tests, and regression analysis show that the differences between the two treatments in terms of the bribe rates, bribe amounts and acceptance rates are not statistically significant.

The punishment behaviour in Indonesia and Singapore is not statistically different across the two treatments either. However, in Singapore the punishment rate in the welfare-enhancing treatment is lower than the punishment rate in the welfare-reducing treatment ( $44 \%$ versus $57 \%)$. These results contrast with the results we have for Australia and Indonesia, where the punishment rate was lower in the welfare-reducing treatment. As in the case of Australia, the average punishment amount in Indonesia is higher in Treatment 3 than in Treatment 2 (\$7.36 as opposed to $\$ 5.59$ respectively), but the difference is only marginally significant and only with a one-tailed test. ${ }^{34}$

In summary, when we consider the impact of the cost of bribery on subject behaviour, we find that the results are culture-specific. In Australia, when the cost of bribery is higher, the propensity to engage in corrupt behaviour is higher, the propensity to punish corrupt behaviour is lower, and the punishment amounts are higher. This implies that those subjects who chose to punish were the ones that were especially concerned about the harm caused by bribery. In Indonesia and Singapore, there are no significant differences in subject behaviour across the two treatments although there were a larger number of subjects who chose not to bribe and to punish under the welfare-reducing treatment. This difference in behaviour across the three countries could be because subjects in Indonesia and Singapore have more immediate experiences of the negative impact of corruption and are, therefore, more willing to condemn it in the welfare reducing treatment.

\footnotetext{
34 The treatment-specific regression results for Indonesia and Singapore, reported in Table 6, Panels B and C, confirm the t-tests.
} 


\section{Concluding Remarks}

Society's attitudes towards corruption play an important role in the reduction of corruption. We have analysed the propensity to engage in and to punish corrupt behaviour in the context of a three-person sequential-move game involving a firm, a government official and a citizen. Our goal has been to understand whether attitudes towards corruption differ across cultures.

Our experiments show that there is a larger cross-cultural variation in the propensity to punish corrupt acts than there is in the propensity to engage in corrupt behaviour. More specifically, our findings can be summarized in the following way. The results from India suggest that exposure to high levels of corruption may lead to a tolerance of and perpetuation of corrupt behaviour. Moreover, comparing Australia and India suggests that lower levels of exposure to corruption may not result in a decrease in the propensity to engage in corrupt behaviour, but may result in an increase in the propensity to punish corrupt behaviour.

Surprisingly, in Indonesia, another country with a high level of corruption according to the traditional measures of corruption, the tendency to engage in and the willingness to punish corrupt behaviour is not much different from Australia. One reading of these results is that the recent democratization and increased press freedom have led to a hardening of attitudes against corruption, at least in the short run. These institutional changes may have created a receptive audience for policies aimed at reducing corruption in the future. This is important since anticorruption measures are more likely to be successful if there is popular support for such measures. A population that is motivated to fight corruption and impose penalties on those who engage in corrupt behaviour is more likely to support the political and bureaucratic reforms aimed at reducing corruption. 
Finally, in Singapore, we find some evidence to suggest that there is a higher propensity to engage in and a lower propensity to punish corrupt behaviour as compared to Australia. However, the punishment rates are higher in Singapore than they are in India. The results from India and Singapore are in line with our hypothesis that the existing level of corruption affects attitudes towards corruption. A comparison of the results from Australia and Singapore suggests that attitudes towards corruption may take a long time to change. Singapore is a country with a relatively recent history of combating corruption. Its success demonstrates that an effective punishment system can go a long way towards reducing corruption. Although the attitudes towards corruption in Singapore seem to have hardened, the subjects in Singapore still seem to display a greater propensity to engage in corrupt acts and a greater tolerance of corruption than Australia.

These results are in line with the declared goals of one of the most successful anticorruption bodies, the Independent Commission Against Corruption (ICAC), which was formed in Hong Kong in 1974: “To change people's behaviour so that they will not engage in corrupt behaviour initially for fear of detection (deterrence), later because they cannot (prevention), and yet later because they do not wish to (attitude change)." 35 The main difference between the ICAC and the previous approaches was that the ICAC combined new incentives with a change in values. Its success has made Hong Kong an example of how promoting ethical values against corruption can work.

Our results also show that a more effective punishment regime leads to less corruption. However, the results are less clear cut when we consider the impact of the cost of bribery on subject behaviour. In Australia, when corruption is welfare reducing, we find that fewer subjects were willing to punish. In contrast, more subjects were willing to punish in the welfare-reducing

\footnotetext{
${ }^{35}$ This example is cited in Hauk and Saez-Marti (2002). Italics are added.
} 
bribe game as compared with the welfare-enhancing bribe game in Indonesia and Singapore. However, the observed differences are not statistically significant.

Our paper suggests several interesting avenues for future research. The results from Indonesia and Singapore suggest that it would be valuable to do further research to define more precisely the role institutional change may play in changing attitudes towards corruption. One way to do this is to investigate how attitudes towards corruption change over time in a given location. Additionally it would be useful to develop theoretical models to understand the mechanism through which institutional change may help reduce corruption. Further research involving other countries with varying levels of corruption would also be valuable 


\section{References}

Abbink, K. and H. Hennig-Schmidt. 2002. "Neutral versus Loaded Instructions in a Bribery Experiment," University of Nottingham, CeDEx Working Paper 2002-13.

Abbink, K., B. Irlenbusch and E. Renner. 2000. "The Moonlighting Game: An Experimental Study on Reciprocity and Retribution," Journal of Economic Behavior and Organization, 42, 265-277.

Abbink, K., B. Irlenbusch and E. Renner. 2002. "An Experimental Bribery Game," Journal of Law, Economics and Organization, 18(2), 428-454.

Alatas, V., L. Cameron, A. Chaudhuri, N. Erkal and L. Gangadharan. 2005. "Gender and Corruption: Insights from an Experimental Analysis," University of Melbourne, mimeo.

Ali, A. M. and H. S. Isse. 2003. "The Determinants of Economic Corruption: A Cross-Country Comparison," Cato Journal, 22(3), 449-466.

Andvig, J. C. and K. Moene. 1990. "How Corruption May Corrupt," Journal of Economic Behaviour and Organization, 13, 63-76.

Bardhan, P. 1997. "Corruption and Development: A Review of Issues," Journal of Economic Literature, 35, 1320-1346.

Barr, A., M. Lindelow and P. Serneels. 2004. "To Serve the Community or Oneself: The Public Servant's Dilemma,” World Bank Policy Research Working Paper, No. 3187.

Bowles, S. and H. Gintis. 2002. "Homo Reciprocans," Nature, 415, 125-128.

Brunetti, A. and B. Weder. 2003. "A Free Press is Bad News for Corruption," Journal of Public Economics, 87, 1801-1824.

Cardenas, J. C. and J. Carpenter. 2005. "Experiments and Economic Development: Lessons from Field Labs in the Developing World," available at http://community.middlebury.edu/ jcarpent/papers.html.

Carpenter, J. and J. C. Cardenas. 2004. "An Inter-Cultural Examination of Cooperation in the Commons," available at http://community.middlebury.edu/ jcarpent/papers.html.

Carpenter, J. and P. H. Matthews. 2004. "Social Reciprocity", IZA Discussion Paper Series, IZA DP No. 1347.

Casari, M. and C. R. Plott. 2003. "Decentralized Management of Common Property Resources: Experiments with a Centuries-Old Institution," Journal of Economic Behaviour and Organization, 51, 217-247. 
Cooper D. and J. Kagel. 2003. "The Impact of Meaningful Context on Strategic Play in Signalling Games," Journal of Economic Behaviour and Organization, 50(3), 311-337.

Croson, R and N. Buchan. 1999. "Gender and Culture: International Experimental Evidence from Trust Games," American Economic Review Papers and Proceedings, 89(2), 386391.

Dey, H. K. 1989. "The Genesis and Spread of Economic Corruption: A Microtheoretic Interpretation," World Development, 17(4), 503-511.

Dollar, D., R. Fisman and R. Gatti. 2001, "Are Women Really the "Fairer" Sex? Corruption and Women in Government," Journal of Economic Behaviour and Organization, 46(4), 42329.

Duffy, J. and J. Ochs. 2005. "Cooperative Behaviour and the Frequency of Social Interaction," available at http://www.pitt.edu/ jduffy/papers/cooperation0405.pdf.

Fehr, E and U. Fischbacher. 2004. "Third-Party Punishment and Social Norms," Evolution and Human Behaviour, 25, 63-87.

Fehr, E., U. Fischbacher and S. Gachter. 2002. "Strong Reciprocity, Human Cooperation and the Enforcement of Social Norms", Human Nature, 13, 1-25.

Fehr, E and S. Gachter. 2002. "Altruistic Punishment in Humans”, Nature, 415, 137-140.

Fehr, E and S. Gachter. 2000. "Cooperation and Punishment in Public Goods Experiments", American Economic Review, 90(4), 980-994.

Frank, B. and G. Schulze. 2000. "Does Economics Make Citizens Corrupt?" Journal of Economic behaviour and Organization, 43, 101-113.

Gentzkow, M., E. L. Glaeser, and C. Goldin. 2004. "The Rise of the Fourth Estate: How Newspapers Became Informative and Why It Mattered," NBER Working Paper 10791.

Glaeser, E. L. and C. Goldin. 2004. "Corruption and Reform: An Introduction,” NBER Working Paper 10775.

Harrison , G. W. and J. List. 2004. "Field Experiments," Journal of Economic Literature, 42, 1009-1055.

Hauk, E. and M. Saez-Marti. 2002. "On the Cultural Transmission of Corruption," Journal of Economic Theory," 107(2), 311-335.

Henrich, J., R. Boyd, S. Bowles, C. Camerer, E. Fehr, and H. Gintis. 2004. Foundations of Human Sociality, Oxford University Press. 
Kandori, M. 1992. "Social Norms and Community Enforcement," Review of Economic Studies, $59,63-80$.

Kaufmann, D. and S.-J. Wei. 1999. "Does 'Grease Money' Speed Up the Wheels of Commerce?” NBER Working Paper 7093.

Klitgaard, R. E. 1988. Controlling Corruption, University of California Press.

Lui, F. T. 1986. "A Dynamic Model of Corruption Deterrence," Journal of Public Economics, $31,215-236$.

Masclet, D., C. Noussair, S. Tucker, and M.-C. Villeval. 2003. "Monetary and Nonmonetary Punishment in the Voluntary Contributions Mechanism," American Economic Review, 93, 366-380.

Mauro, P. 1995. “Corruption and Growth,” Quarterly Journal of Economics, 110, 681- 712.

Nas, T. F., A. C. Price, and C. T. Weber. 1986. “A Policy-Oriented Theory of Corruption," The American Political Science Review, 80(1), 107-119.

Rose-Ackerman, S. 1978. Corruption: A Study in Political Economy, New York: Academic Press.

Roth, A., V. Prasnikar, M. Okuno-Fujiwara and S. Zamir. 1991. "Bargaining and Market Behaviour in Jerusalem, Ljubljana, Pittsburgh and Tokyo: An Experimental Study," American Economic Review, 81, 1068-1095.

Sah, R. K. 1988. "Persistence and Pervasiveness of Corruption: New Perspectives," Yale University, Economic Growth Center Discussion Paper \#560.

Swamy, A., S. Knack., Y. Lee and O. Azfar. 2001. "Gender and Corruption," Journal of Development Economics, 64(1), 25-55.

Tirole, J. 1996. "A Theory of Collective Reputation (with Applications to the Persistence of Corruption and Firm Quality)," Review of Economic Studies, 63, 1-22.

Treisman, D. 2000. "The Causes of Corruption: A Cross-National Study," Journal of Public Economics, 76, 399-457. 


\section{Figure 1: The Welfare-Enhancing Bribe Game}

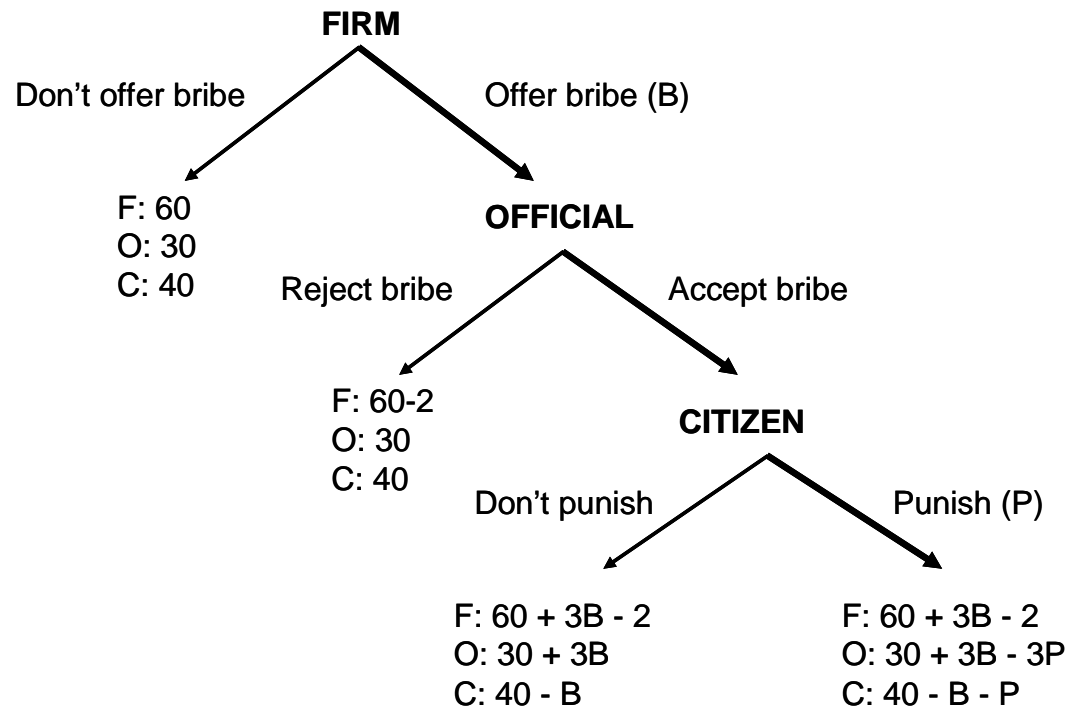

Figure 2: The Welfare-Reducing Bribe Game

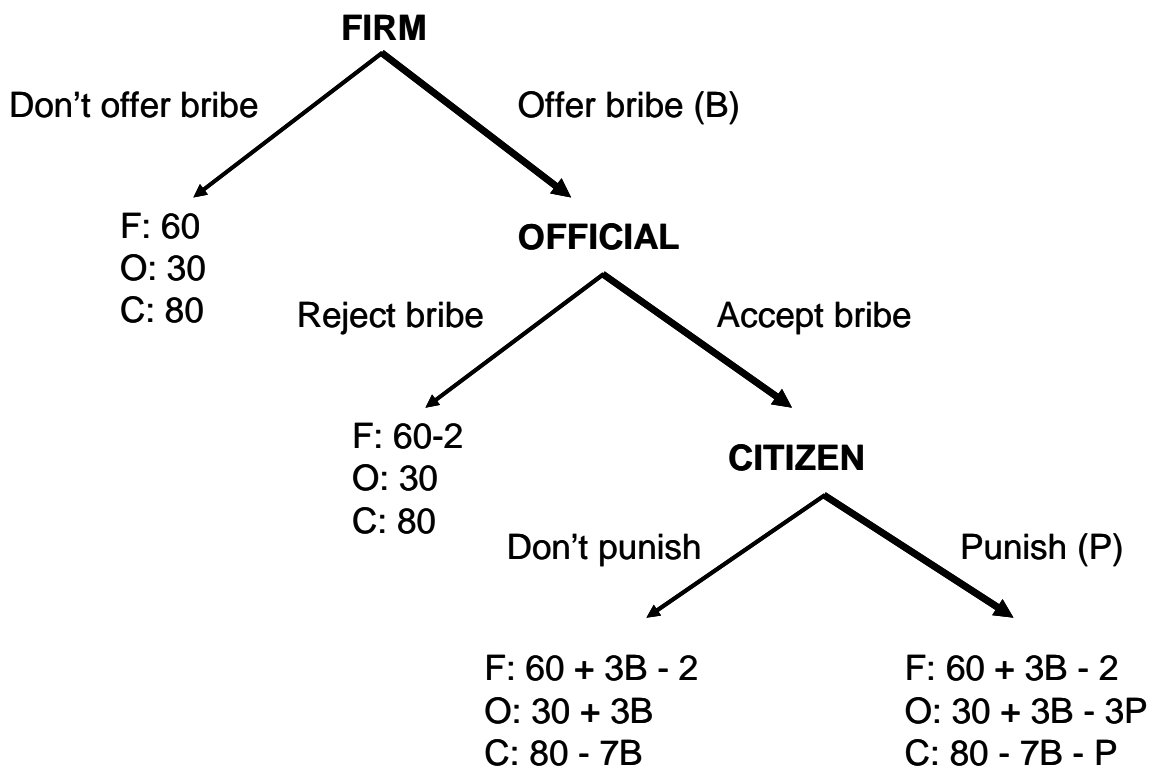




\section{Figure 3: Overview of the Results}

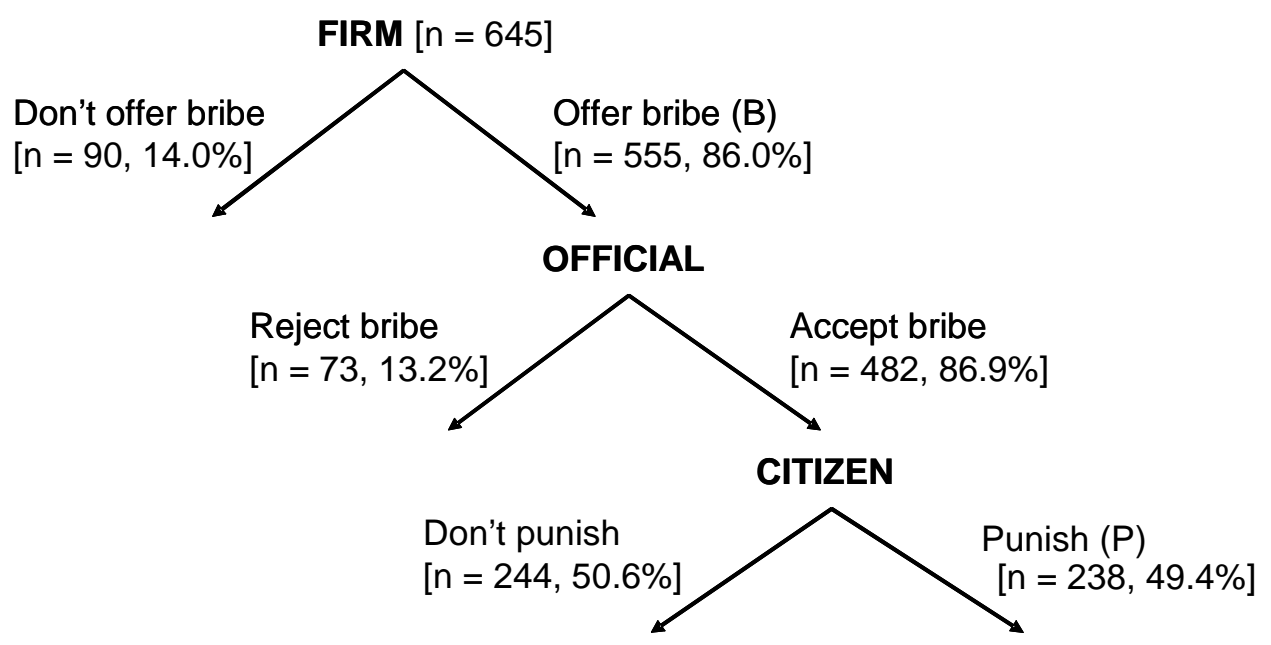


Figure 4: Cultural Effects - Bribe Behaviour

Figure 4A: Australia and India (Treatment 1)
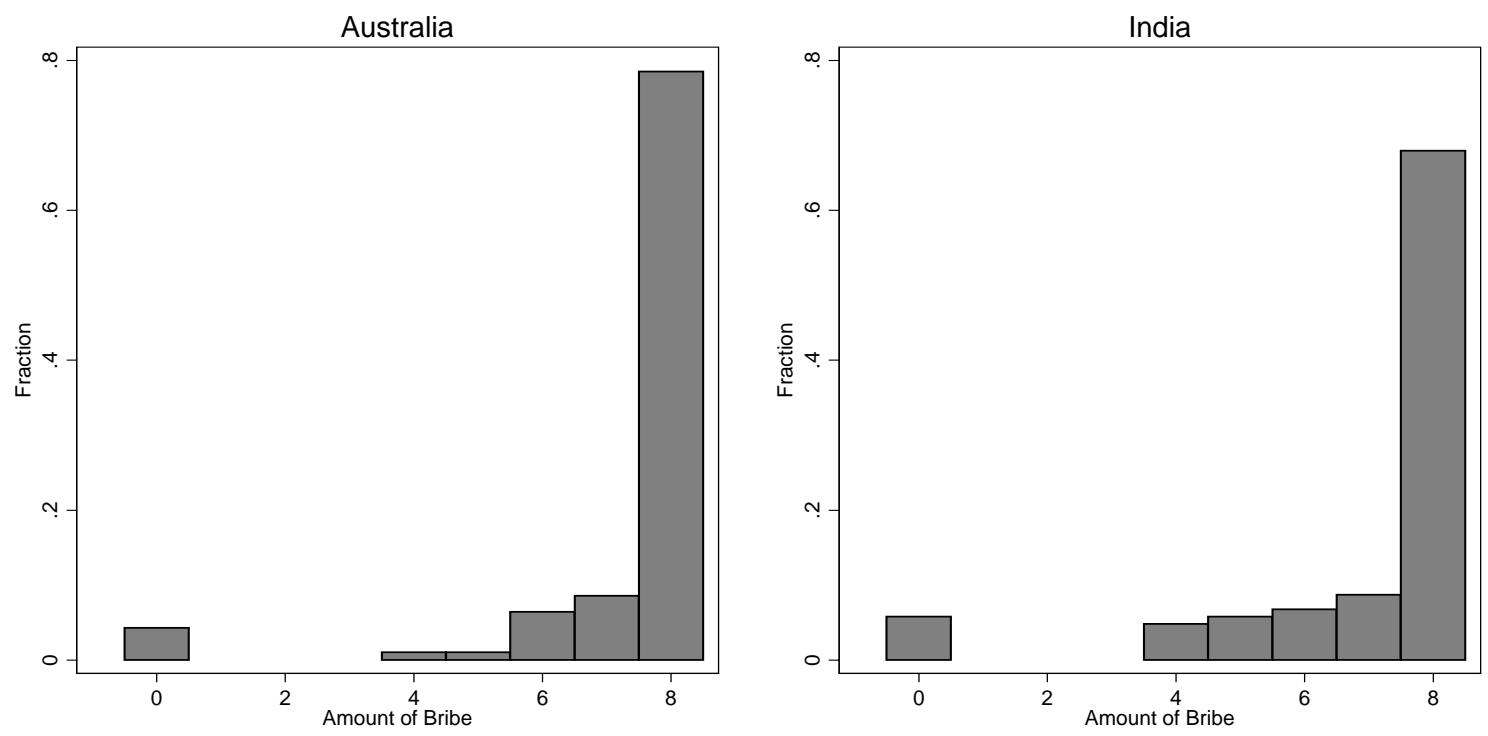

Figure 4B: Australia, Indonesia and Singapore (Treatments 2 and 3)
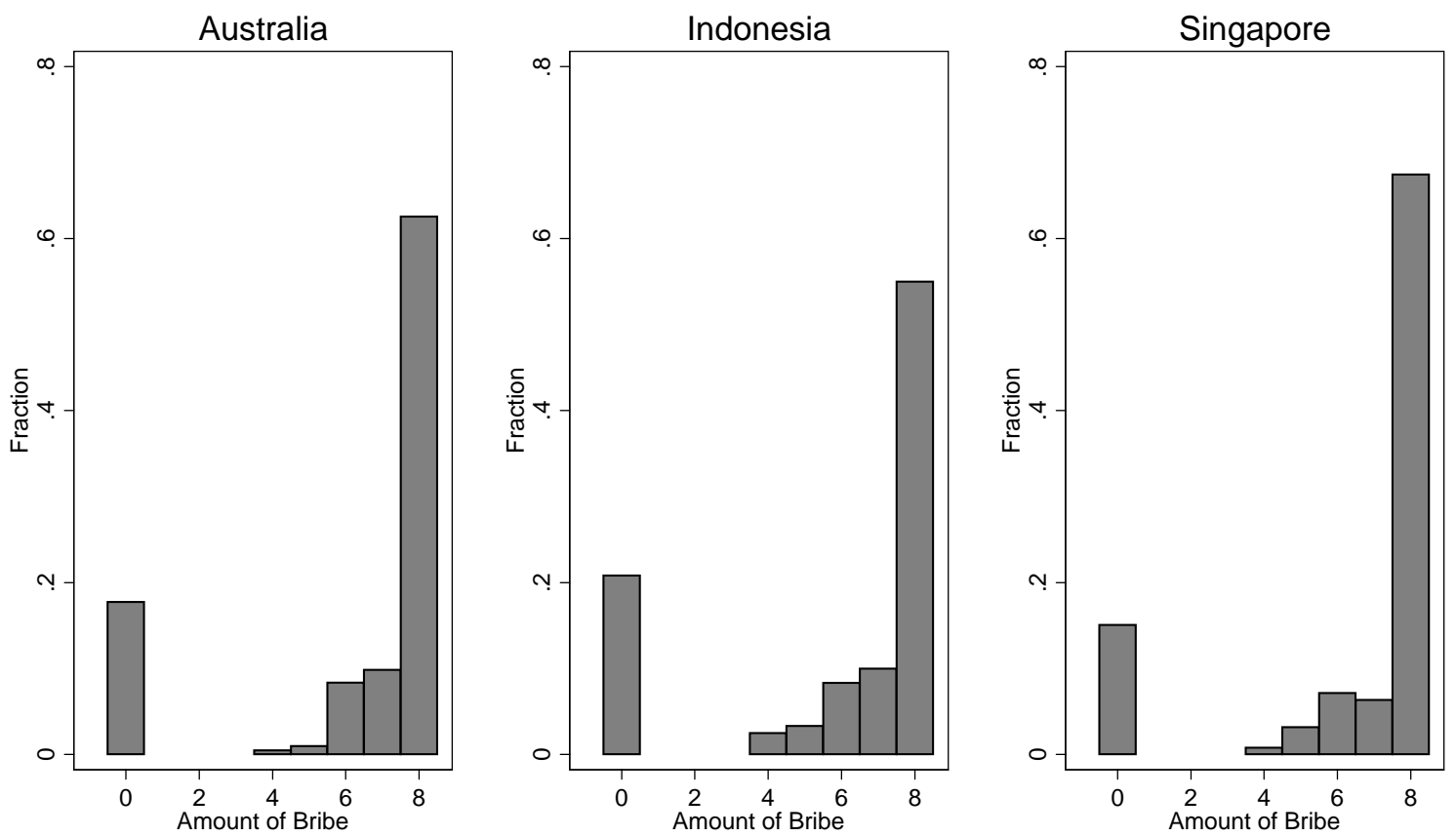
Figure 5: Cultural Effects - Punishment Behaviour

Figure 5A: Australia and India (Treatment 1)
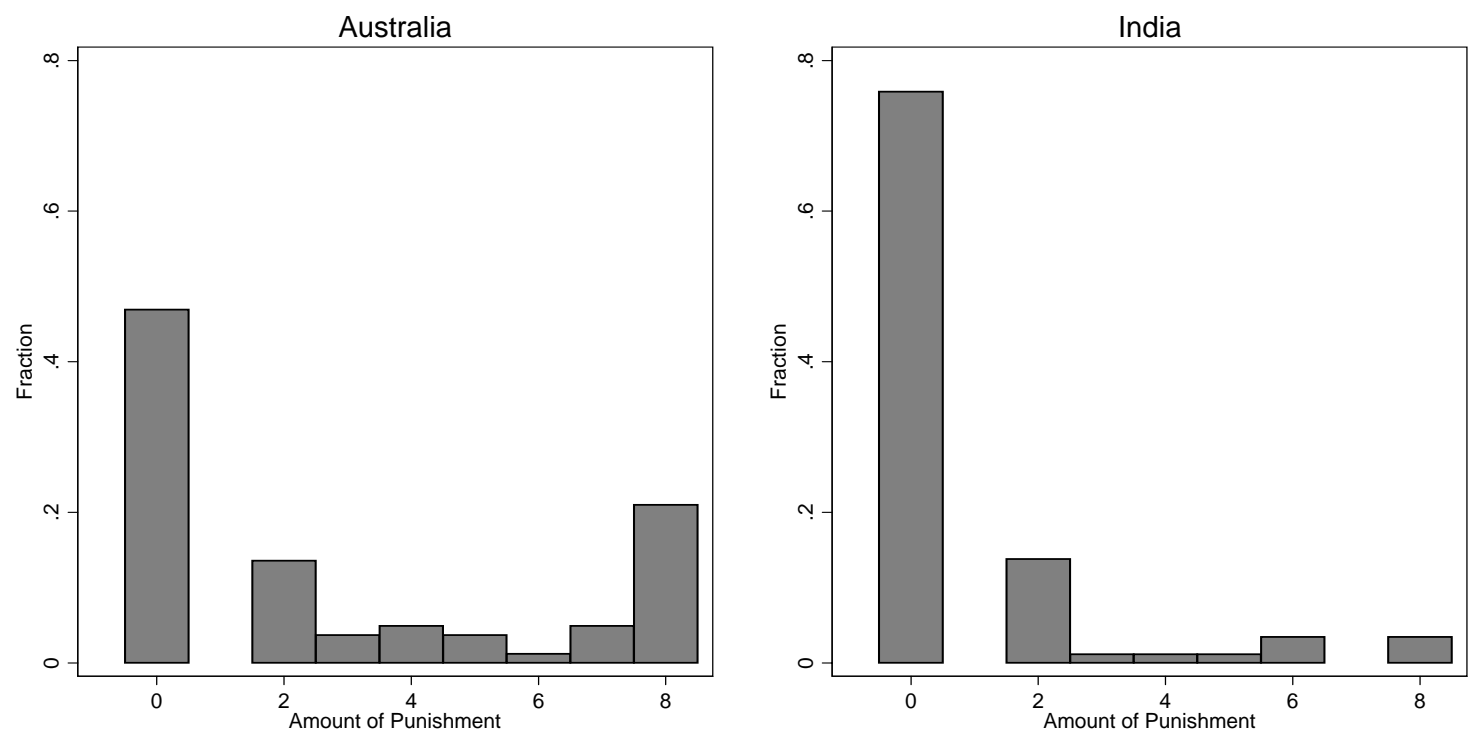

Figure 5B: Australia, Indonesia and Singapore (Treatments 2 and 3)
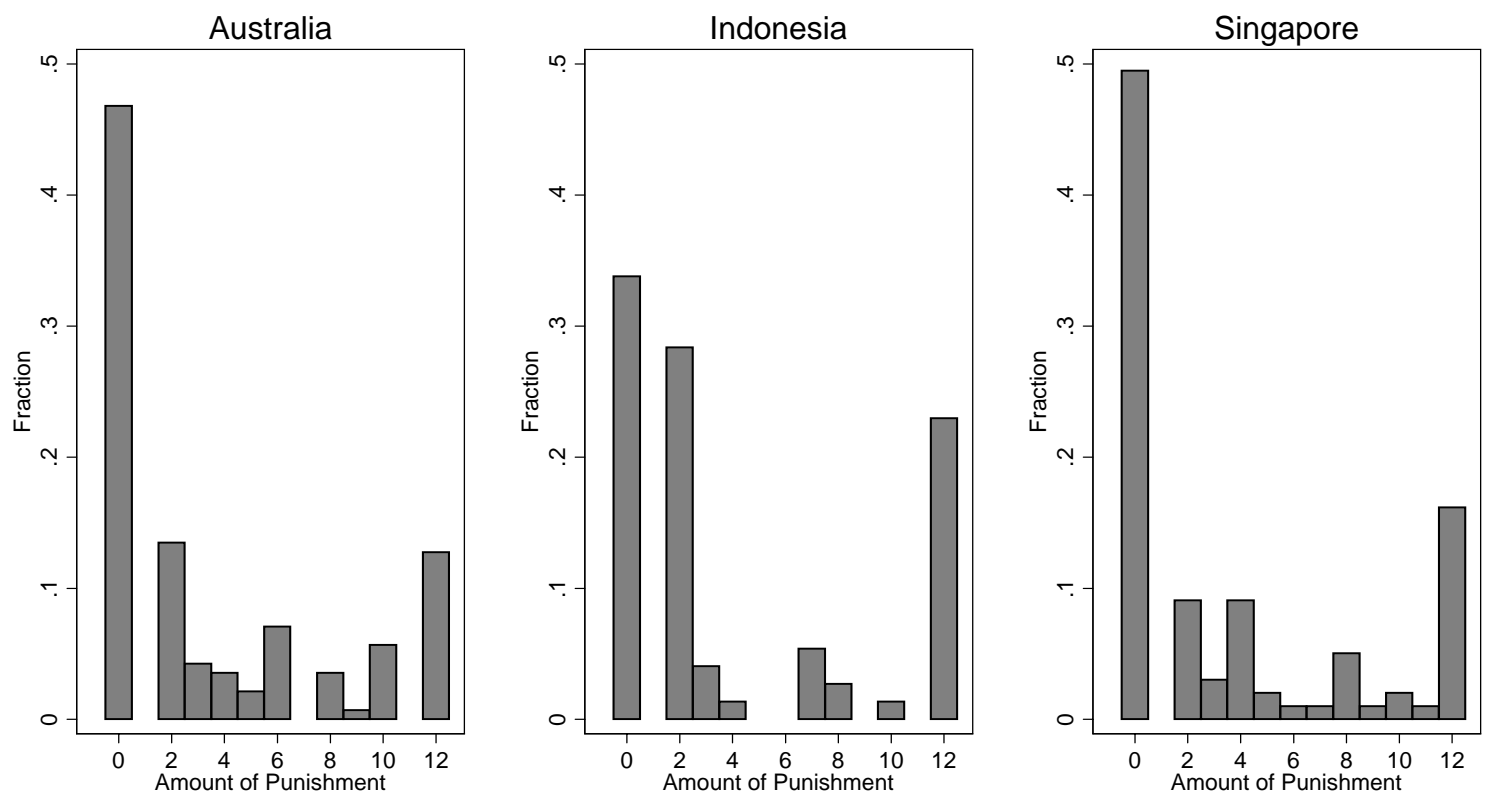
Figure 6: Treatment Effects (Australia)

Figure 6A: Bribe Behaviour
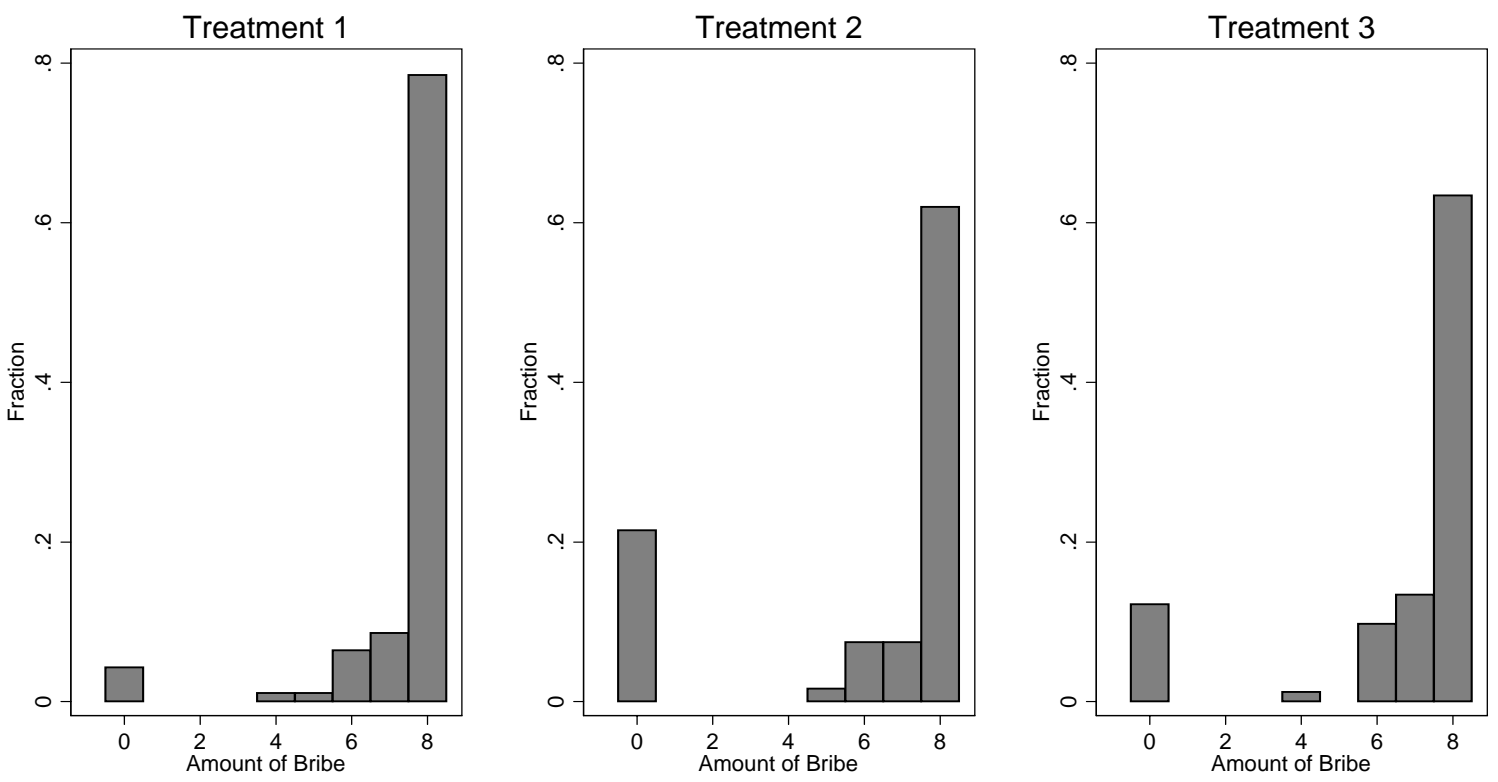

Figure 6B: Punishment Behaviour
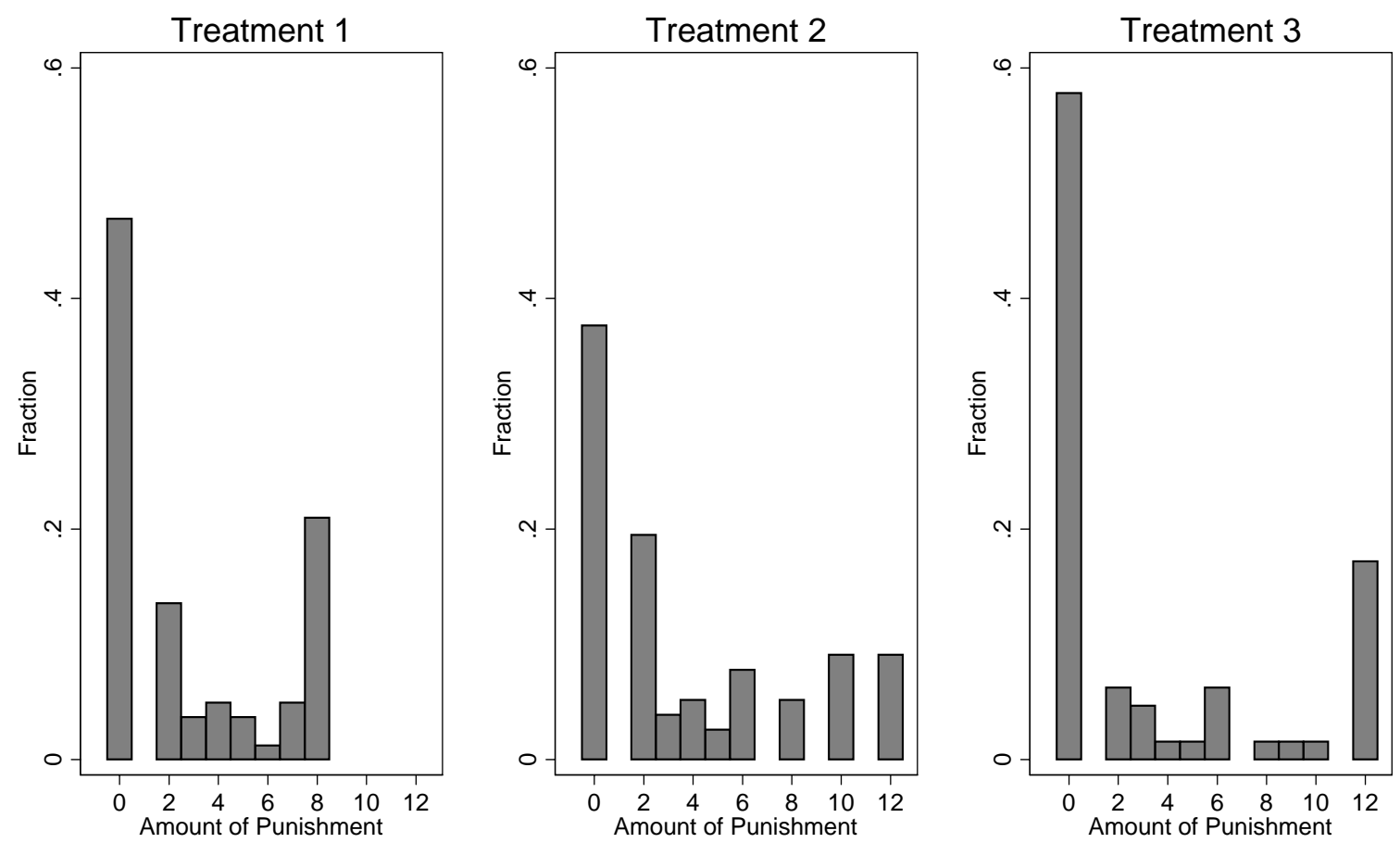
Table 1: Experimental Design

\begin{tabular}{|c|c|c|c|}
\hline & $\begin{array}{l}\text { Low Punishment / } \\
\text { Efficiency-enhancing } \\
\text { (Treatment 1) }\end{array}$ & $\begin{array}{l}\text { High Punishment/ } \\
\text { Efficiency-enhancing } \\
\text { (Treatment 2) }\end{array}$ & $\begin{array}{c}\text { High Punishment/ } \\
\text { Efficiency-reducing } \\
\text { (Treatment 3) }\end{array}$ \\
\hline $\begin{array}{l}\text { Australia } \\
(\mathrm{N}=\mathbf{8 8 8})\end{array}$ & $\begin{array}{c}\mathrm{N}=279 \\
\text { Games }=93\end{array}$ & $\begin{array}{c}\mathrm{N}=363 \\
\text { Games }=121\end{array}$ & $\begin{array}{c}\mathrm{N}=246 \\
\text { Games }=82\end{array}$ \\
\hline $\begin{array}{c}\text { India } \\
(N=309)\end{array}$ & $\begin{array}{c}\mathrm{N}=309 \\
\text { Games }=103\end{array}$ & -- & -- \\
\hline $\begin{array}{l}\text { Indonesia } \\
(\mathrm{N}=360)\end{array}$ & -- & $\begin{array}{c}\mathrm{N}=180 \\
\text { Games }=60\end{array}$ & $\begin{array}{c}\mathrm{N}=180 \\
\text { Games }=60\end{array}$ \\
\hline $\begin{array}{l}\text { Singapore } \\
(N=378)\end{array}$ & -- & $\begin{array}{c}\mathrm{N}=195 \\
\text { Games }=65\end{array}$ & $\begin{array}{c}\mathrm{N}=183 \\
\text { Games }=61\end{array}$ \\
\hline $\begin{array}{c}\text { Total } \\
(\mathrm{N}=1935)\end{array}$ & $\begin{array}{c}\mathrm{N}=588 \\
\text { Games }=196\end{array}$ & $\begin{array}{c}\mathrm{N}=738 \\
\text { Games }=246\end{array}$ & $\begin{array}{c}\mathrm{N}=609 \\
\text { Games }=203\end{array}$ \\
\hline
\end{tabular}




\section{Table 2: Differences in Means (t-tests) - Cultural Effects}

(i)

$\%$ of firms bribing

Bribe amount (if $>0$ )

$\%$ of officials accepting

$\%$ of citizens punishing

Punishment amount (if $>0$ )

(ii)

$\%$ of firms bribing

Bribe amount (if $>0$ )

$\%$ of officials accepting

$\%$ of citizens punishing

Punishment amount (if $>0$ )

(iii)

$\%$ of firms bribing

Bribe amount (if $>0$ )

$\%$ of officials accepting

$\%$ of citizens punishing

Punishment amount (if $>0$ )

(iv)

$\%$ of firms bribing

Bribe amount (if $>0$ )

$\%$ of officials accepting

$\%$ of citizens punishing

Punishment amount (if $>0$ )

(v)

$\%$ of firms bribing

Bribe amount (if $>0$ )

$\%$ of officials accepting

$\%$ of citizens punishing

Punishment amount (if $>0$ )

(vi)

$\%$ of firms bribing

Bribe amount (if $>0$ )

$\%$ of officials accepting

$\%$ of citizens punishing

Punishment amount (if $>0$ )

(vii)

$\%$ of firms bribing

Bribe amount (if $>0$ )

$\%$ of officials accepting

$\%$ of citizens punishing

Punishment amount (if $>0$ )

\begin{tabular}{ccc}
$\begin{array}{c}\text { Australia } \\
\text { (Treatment 1) }\end{array}$ & $\begin{array}{c}\text { India } \\
\text { (Treatment 1) }\end{array}$ & p-value \\
\hline 95.70 & 94.17 & 0.63 \\
7.70 & 7.37 & 0.03 \\
91.01 & 89.69 & 0.76 \\
53.09 & 24.14 & 0.0001 \\
5.40 & 3.71 & 0.01 \\
Australia & Indonesia & p-value \\
(Treatment 2) & (Treatment 2) & \\
\hline 78.51 & 80.00 & 0.82 \\
7.65 & 7.50 & 0.30 \\
81.05 & 77.08 & 0.58 \\
62.34 & 72.97 & 0.27 \\
5.98 & 5.59 & 0.69 \\
Australia & Indonesia & p-value \\
(Treatment 3) & (Treatment 3) & 0.13 \\
\hline 87.80 & 78.33 & 0.16 \\
7.57 & 7.32 & 0.13 \\
88.89 & 78.72 & 0.10 \\
42.19 & 59.46 & 0.76
\end{tabular}

Australia

(Treatment 2)

Singapore

\begin{tabular}{ccc} 
(Treatment 2) & $($ Treatment 2) & p-value \\
\hline 78.51 & 86.15 & 0.21 \\
7.65 & 7.63 & 0.83 \\
81.05 & 89.29 & 0.18 \\
62.34 & 44.00 & 0.04 \\
5.98 & 7.23 & 0.21
\end{tabular}

Australia

(Treatment 3)

Singapore

\begin{tabular}{ccc} 
(Treatment 3) & (Treatment 3) & p-value \\
\hline 87.80 & 83.61 & 0.48 \\
7.57 & 7.59 & 0.90 \\
88.89 & 96.08 & 0.15 \\
42.19 & 57.14 & 0.12 \\
7.74 & 7.11 & 0.58
\end{tabular}

Indonesia

(Treatment 2)

Singapore

80.00

7.50

77.08

72.97

5.59

(Treatment 2)

p-value

Indonesia

(Treatment 3)

86.15

7.63

89.29

44.00

0.48

0.10

7.23

0.01

0.19

78.33

7.32

78.72

Singapore

(Treatment 3)

p-value

83.61

7.59

0.46

0.19

96.08

0.01

59.46

57.14

0.83

7.36

0.84 


\section{Table 3: Differences in Means (t-tests) - Treatment Effects}

\section{A. Australia}

\section{(i) \\ $\%$ firms bribing}

Bribe Amount (if $>0$ )

$\%$ officials accepting

$\%$ citizens punishing

Punishment Amount (if $>0$ )

\begin{tabular}{ccc} 
Treatment 1 & Treatment 2 & p-value \\
\hline 95.70 & 78.51 & 0.0003 \\
7.70 & 7.65 & 0.69 \\
91.01 & 81.05 & 0.05 \\
53.09 & 62.34 & 0.24 \\
5.40 & 5.98 & 0.40
\end{tabular}

(ii)

$\%$ firms bribing

Bribe Amount (if $>0$ )

$\%$ officials accepting

$\%$ citizens punishing

\begin{tabular}{ccc} 
Treatment 2 & Treatment 3 & p-value \\
\hline 78.51 & 87.80 & 0.09 \\
7.65 & 7.57 & 0.49 \\
81.05 & 88.89 & 0.17 \\
62.34 & 42.19 & 0.02 \\
5.98 & 7.74 & 0.06
\end{tabular}

Punishment Amount (if $>0$ )

5.98

7.74

0.06

\section{B. Singapore}

\begin{tabular}{lccc} 
(iii) & Treatment 2 & Treatment 3 & p-value \\
\cline { 2 - 4 } \% firms bribing & 86.15 & 83.61 & 0.69 \\
Bribe Amount (if $>0$ ) & 7.63 & 7.59 & 0.83 \\
\% officials accepting & 89.29 & 96.08 & 0.19 \\
\% citizens punishing & 44.00 & 57.14 & 0.19 \\
Punishment Amount (if $>0$ ) & 7.23 & 7.11 & 0.92 \\
& & & \\
C. Indonesia & & Treatment 3 & p-value \\
\hline (iv) & Treatment 2 & 78.33 & 0.82 \\
\% firms bribing & 80.00 & 7.32 & 0.40 \\
Bribe Amount (if $>0$ ) & 7.50 & 78.72 & 0.85 \\
\% officials accepting & 77.08 & 59.46 & 0.22 \\
\% citizens punishing & 72.97 & 7.36 & 0.18 \\
Punishment Amount $($ if $>0$ ) & 5.59 & &
\end{tabular}


Table 4: Multivariate Regression Results - Cultural Effects

A. Australia vs. India vs. Indonesia vs. Singapore, All Treatments, Pooled Regression (Australia and Treatment 2 are the reference dummies.)

\begin{tabular}{|c|c|c|c|c|c|c|c|c|c|c|c|c|c|}
\hline & \multicolumn{2}{|c|}{ Bribe $(0 / 1)$} & & \multicolumn{2}{|c|}{ Bribe Amount } & \multicolumn{2}{|c|}{ Accept $(0 / 1)$} & \multicolumn{3}{|c|}{ Punish (0/1) } & \multicolumn{3}{|c|}{ Punishment Amount } \\
\hline & 1 & 2 & & 3 & 4 & 5 & 6 & 7 & 8 & & 9 & 10 & \\
\hline & M. Effect* & p-value & & Coeff & p-value & M. Effect" & $\begin{array}{c}\mathrm{p}- \\
\text { value }\end{array}$ & M. Effect* & $\begin{array}{c}\text { p- } \\
\text { value }\end{array}$ & & Coeff & p-value & \\
\hline Treatment 1 & 0.135 & 0.003 & $\Delta$ & 0.028 & 0.83 & 0.075 & $0.09 \quad \#$ & -0.044 & 0.56 & & -0.906 & 0.23 & \\
\hline Treatment 3 & 0.021 & 0.46 & & -0.091 & 0.34 & 0.048 & 0.13 & -0.078 & 0.18 & & 1.148 & 0.05 & $*$ \\
\hline India & 0.026 & 0.71 & & -0.424 & 0.02 & -0.013 & 0.84 & -0.248 & 0.01 & $\Delta$ & -2.602 & 0.02 & $*$ \\
\hline Indonesia & 0.037 & 0.41 & & -0.300 & 0.08 & -0.043 & 0.45 & 0.123 & 0.18 & & -1.249 & 0.16 & \\
\hline Singapore & 0.080 & 0.05 & $*$ & -0.085 & 0.61 & 0.086 & 0.07 & -0.049 & 0.57 & & -0.512 & 0.56 & \\
\hline Male & 0.049 & 0.06 & $\#$ & 0.064 & 0.42 & 0.025 & 0.38 & -0.062 & 0.19 & & 0.900 & 0.08 & $\#$ \\
\hline Econ major & 0.039 & 0.19 & & 0.099 & 0.25 & 0.062 & 0.05 & -0.159 & 0.003 & $\Delta$ & 0.045 & 0.94 & \\
\hline$\%$ life out of Australia & 0.102 & 0.05 & $*$ & -0.122 & 0.47 & 0.001 & 0.63 & -0.019 & 0.83 & & -1.323 & 0.12 & \\
\hline Bribe amount & & & & & & 0.009 & 0.53 & -0.010 & 0.70 & & 0.337 & 0.25 & \\
\hline const & & & & 7.693 & 0.00 & & & & & & 4.149 & 0.07 & $\#$ \\
\hline R-squared & \multicolumn{2}{|c|}{0.063} & & \multicolumn{2}{|c|}{$\begin{array}{c}0.01 \\
553\end{array}$} & \multicolumn{2}{|c|}{$\begin{array}{c}0.047 \\
554\end{array}$} & \multicolumn{2}{|c|}{$\begin{array}{c}0.069 \\
481\end{array}$} & & \multicolumn{3}{|c|}{$\begin{array}{c}0.066 \\
238\end{array}$} \\
\hline
\end{tabular}

B. Australia vs. India, Treatment 1 (Australia is the reference dummy.)

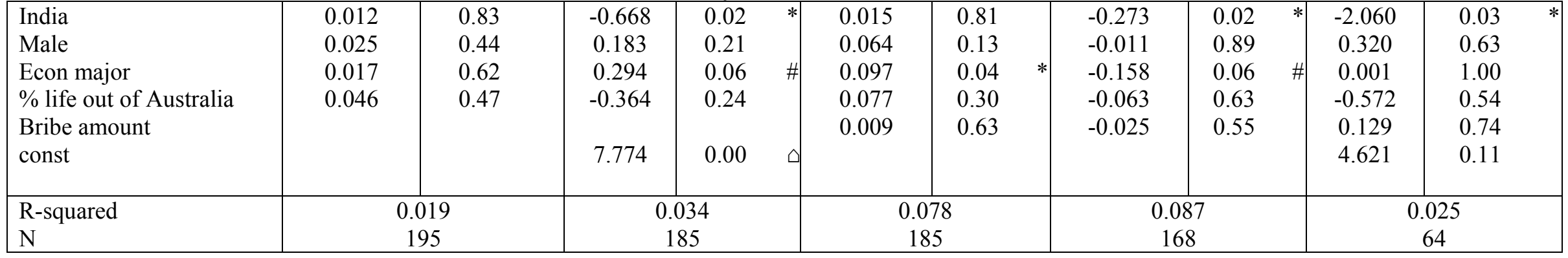


C. Australia vs. Indonesia vs. Singapore, Treatment 2 (Australia is the reference dummy.)

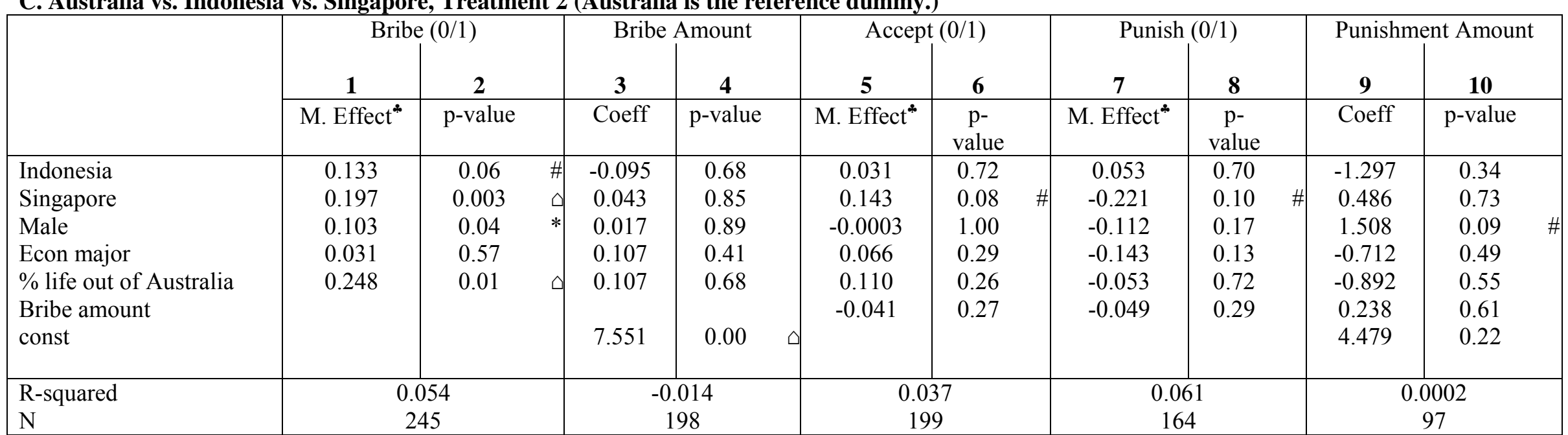

D. Australia vs. Indonesia vs. Singapore, Treatment 3 (Australia is the reference dummy.)

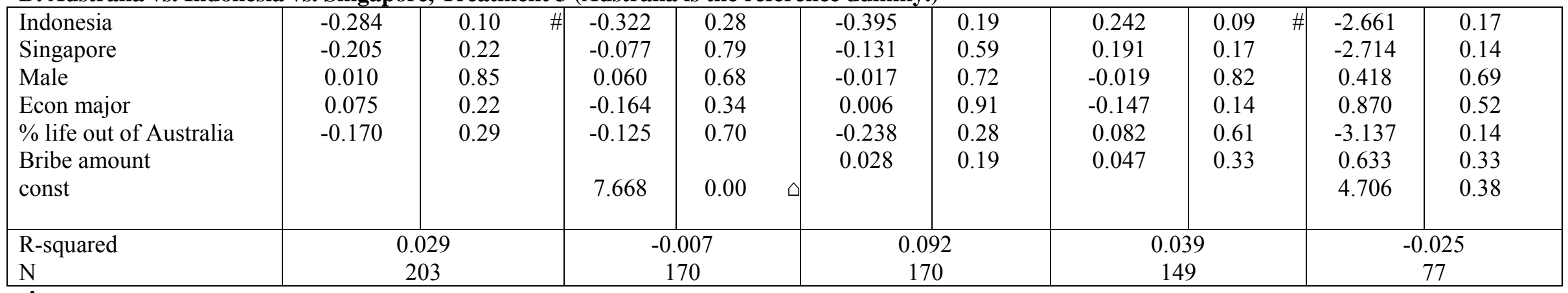

* We report marginal effects for the probits. * $(\#, \triangle)$ denotes statistical significance at the 5\% (10\%, 1\%) level. 
E. Singapore vs. Australia vs. Indonesia, Treatment 2 (Singapore is the reference dummy.)

\begin{tabular}{|c|c|c|c|c|c|c|c|c|c|c|c|c|c|}
\hline & \multicolumn{3}{|c|}{ Bribe $(0 / 1)$} & \multicolumn{2}{|c|}{ Bribe Amount } & \multicolumn{2}{|c|}{ Accept (0/1) } & \multicolumn{3}{|c|}{ Punish (0/1) } & \multicolumn{3}{|c|}{ Punishment Amount } \\
\hline & 1 & 2 & & 3 & 4 & 5 & 6 & 7 & 8 & & 9 & 10 & \\
\hline & M. Effect* & p-value & & Coeff & p-value & M. Effect ${ }^{*}$ & $\begin{array}{c}\mathrm{p}- \\
\text { value }\end{array}$ & M. Effect* & $\begin{array}{c}\mathrm{p}- \\
\text { value }\end{array}$ & & Coeff & p-value & \\
\hline Australia & -0.244 & 0.003 & $\Delta$ & -0.043 & 0.85 & -0.168 & $0.08 \quad \#$ & 0.215 & 0.10 & $\#$ & -0.486 & 0.73 & \\
\hline Indonesia & -0.097 & 0.21 & & -0.138 & 0.40 & -0.151 & $0.08 \quad \#$ & 0.251 & 0.01 & $\Delta$ & -1.783 & 0.13 & \\
\hline Male & 0.103 & 0.04 & $*$ & 0.017 & 0.89 & -0.0003 & 1.00 & -0.112 & 0.17 & & 1.508 & 0.09 & \# \\
\hline Econ major & 0.031 & 0.57 & & 0.107 & 0.41 & 0.066 & 0.29 & -0.143 & 0.13 & & -0.712 & 0.49 & \\
\hline$\%$ life out of Australia & 0.248 & 0.01 & $\Delta$ & 0.107 & 0.68 & 0.110 & 0.26 & -0.053 & 0.72 & & -0.892 & 0.55 & \\
\hline Bribe amount & & & & & & -0.041 & 0.27 & -0.049 & 0.29 & & 0.238 & 0.61 & \\
\hline const & & & & 7.594 & 0.00 & & & & & & 4.965 & 0.18 & \\
\hline R-squared & \multirow{2}{*}{\multicolumn{3}{|c|}{$\begin{array}{c}0.054 \\
245\end{array}$}} & \multirow{2}{*}{\multicolumn{2}{|c|}{$\begin{array}{c}-0.014 \\
109\end{array}$}} & \multicolumn{2}{|c|}{0.037} & \multirow{2}{*}{\multicolumn{3}{|c|}{$\begin{array}{c}0.061 \\
164\end{array}$}} & \multicolumn{3}{|c|}{0.0002} \\
\hline $\mathrm{N}$ & & & & 198 & & \multicolumn{2}{|c|}{199} & & & & \multicolumn{3}{|c|}{97} \\
\hline
\end{tabular}

\section{F. Singapore vs. Australia vs. Indonesia, Treatment 3 (Singapore is the reference dummy.)}

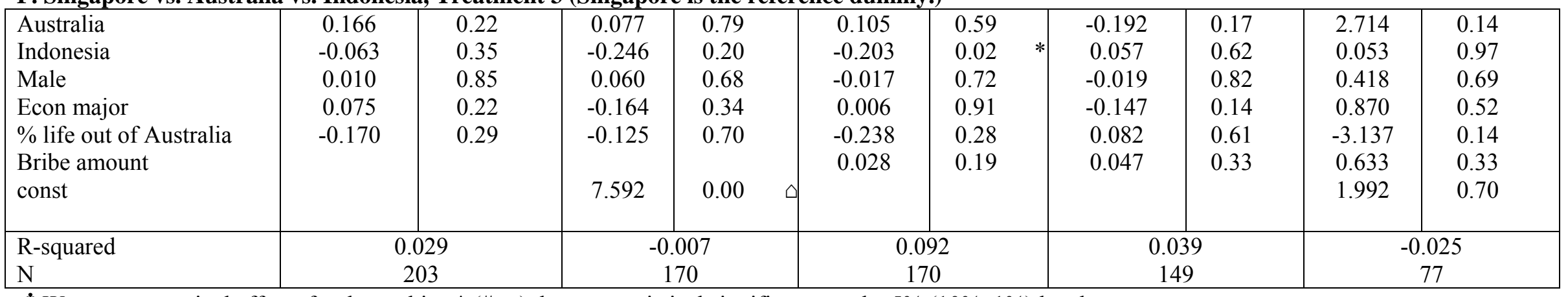

* We report marginal effects for the probits. * $(\#, \triangle)$ denotes statistical significance at the 5\% (10\%, 1\%) level. 
Table 5: Survey Responses: Reasons for Punishing/Not Punishing

A. Reasons for punishing (as a percentage of those who had a chance to punish)

\begin{tabular}{|l|c|c|c|c|c|}
\hline & Overall & \multicolumn{4}{|c|}{ Location } \\
\hline & & Australia & India & Indonesia & Singapore \\
\hline $\begin{array}{l}\text { Moral } \\
\text { responsibility }\end{array}$ & $27.4 \%$ & $32.0 \%$ & $13.8 \%$ & $39.2 \%$ & $20.2 \%$ \\
\hline reduce corruption & $14.3 \%$ & $17.6 \%$ & $8.0 \%$ & $20.3 \%$ & $8.1 \%$ \\
\hline fairness & $13.5 \%$ & $12.2 \%$ & $4.6 \%$ & $23.0 \%$ & $15.2 \%$ \\
\hline $\begin{array}{l}\text { Negative } \\
\text { reciprocity }\end{array}$ & $11.0 \%$ & $9.9 \%$ & $0.0 \%$ & $21.6 \%$ & $15.2 \%$ \\
\hline
\end{tabular}

B. Reasons for not punishing (as a percentage of those who did not punish)

\begin{tabular}{|l|c|c|c|c|c|}
\hline profit maximizing & $90.6 \%$ & $91.3 \%$ & $87.9 \%$ & $80.0 \%$ & $98.0 \%$ \\
\hline $\begin{array}{l}\text { difficult to change } \\
\text { the system or } \\
\text { ineffective } \\
\text { punishment system }\end{array}$ & $20.5 \%$ & $10.6 \%$ & $21.2 \%$ & $48.0 \%$ & $18.4 \%$ \\
\hline $\begin{array}{l}\text { bribe may be for a } \\
\text { good purpose or } \\
\text { may be necessary }\end{array}$ & $2.9 \%$ & $3.8 \%$ & $0.0 \%$ & $12.0 \%$ & $0.0 \%$ \\
\hline
\end{tabular}


Table 6: Multivariate Regression Results - Treatment Effects

A. Australia (Treatments 1, 2 and 3; Treatment 2 is the reference dummy.)

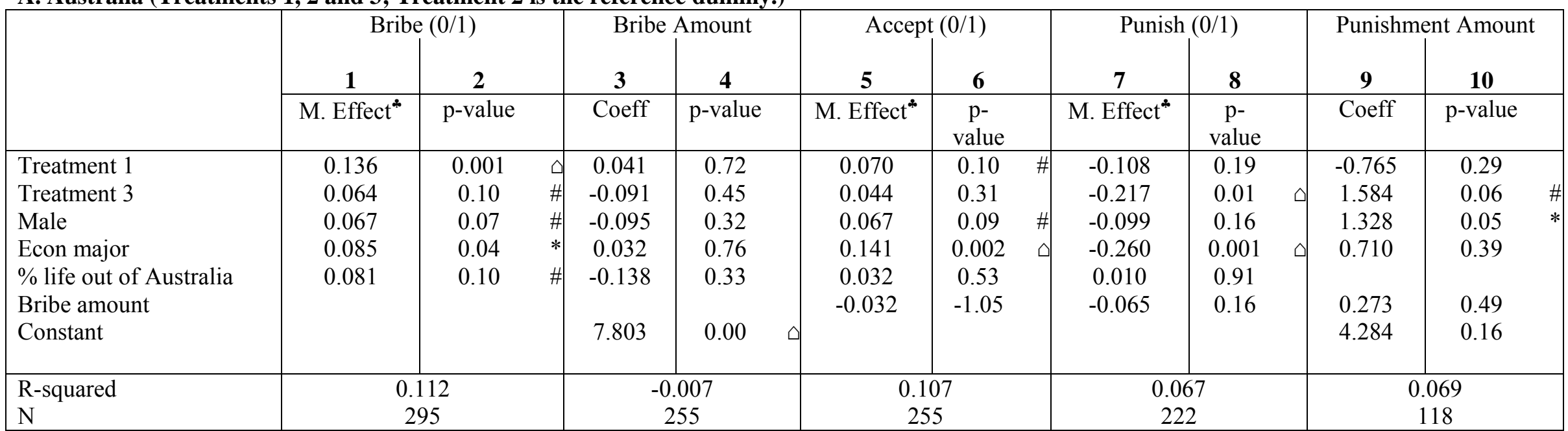

B. Singapore (Treatments 2 and 3; Treatment 3 is the reference dummy.)

\begin{tabular}{|c|c|c|c|c|c|c|c|c|c|c|c|}
\hline $\begin{array}{l}\text { Treatment } 2 \\
\text { Male } \\
\text { Econ major } \\
\text { Bribe amount } \\
\text { Constant }\end{array}$ & $\begin{array}{l}0.023 \\
0.010 \\
0.031\end{array}$ & $\begin{array}{l}0.72 \\
0.89 \\
0.71\end{array}$ & $\begin{array}{c}0.040 \\
0.301 \\
-0.058 \\
7.485\end{array}$ & $\begin{array}{ll}0.81 \\
0.09 \\
0.79 \\
0.00\end{array}$ & $\begin{array}{c}-0.064 \\
-0.040 \\
0.038 \\
-0.040\end{array}$ & $\begin{array}{l}0.17 \\
0.38 \\
0.48 \\
0.35\end{array}$ & $\begin{array}{c}-0.108 \\
-0.142 \\
-0.120 \\
0.014\end{array}$ & $\begin{array}{l}0.29 \\
0.17 \\
0.37 \\
0.80\end{array}$ & $\begin{array}{c}0.089 \\
-1.043 \\
2.673 \\
0.134 \\
6.084\end{array}$ & $\begin{array}{l}0.94 \\
0.40 \\
0.13 \\
0.85 \\
0.28\end{array}$ & $\#$ \\
\hline $\begin{array}{l}\text { R-squared } \\
N\end{array}$ & \multicolumn{2}{|c|}{$\begin{array}{c}0.003 \\
126\end{array}$} & \multicolumn{2}{|c|}{$\begin{array}{c}0.003 \\
107\end{array}$} & \multicolumn{2}{|c|}{$\begin{array}{c}0.074 \\
107\end{array}$} & \multicolumn{2}{|c|}{$\begin{array}{c}0.033 \\
99\end{array}$} & \multicolumn{3}{|c|}{$\begin{array}{c}-0.016 \\
50\end{array}$} \\
\hline
\end{tabular}

* We report marginal effects for the probits. * (\#, $\triangle)$ denotes statistical significance at the 5\% $(10 \%, 1 \%)$ level. 
C. Indonesia (Treatments 2 and 3; Treatment 3 is the reference dummy.)

\begin{tabular}{|c|c|c|c|c|c|c|c|c|c|c|c|}
\hline & Brib & $(0 / 1)$ & Bribe & Amount & Accept & $0 / 1)$ & Punisl & $0 / 1)$ & Punishn & it Amoun & \\
\hline & 1 & 2 & 3 & 4 & 5 & 6 & 7 & 8 & 9 & 10 & \\
\hline & M. Effect" & p-value & Coeff & p-value & M. Effect" & $\begin{array}{c}\text { p- } \\
\text { value }\end{array}$ & M. Effect" & $\begin{array}{c}\text { p- } \\
\text { value }\end{array}$ & Coeff & p-value & \\
\hline $\begin{array}{l}\text { Treatment } 2 \\
\text { Male } \\
\text { Econ major } \\
\text { Bribe amount } \\
\text { Constant }\end{array}$ & $\begin{array}{c}0.008 \\
0.048 \\
-0.001\end{array}$ & $\begin{array}{l}0.92 \\
0.53 \\
0.99\end{array}$ & $\begin{array}{c}0.197 \\
-0.211 \\
0.253 \\
\\
7.328\end{array}$ & $\begin{array}{l}0.36 \\
0.33 \\
0.27 \\
0.00\end{array}$ & $\begin{array}{c}-0.055 \\
-0.026 \\
0.157 \\
-0.051\end{array}$ & $\begin{array}{l}0.53 \\
0.77 \\
0.11 \\
0.18\end{array}$ & $\begin{array}{c}0.184 \\
-0.024 \\
0.165 \\
0.039\end{array}$ & $\begin{array}{l}0.12 \\
0.84 \\
0.23 \\
0.50\end{array}$ & $\begin{array}{c}-2.597 \\
2.740 \\
-2.943 \\
0.601 \\
2.785\end{array}$ & $\begin{array}{l}0.05 \\
0.04 \\
0.06 \\
0.38 \\
0.61\end{array}$ & $\begin{array}{l}* \\
* \\
\#\end{array}$ \\
\hline $\begin{array}{l}\text { R-squared } \\
\mathrm{N}\end{array}$ & & & & $\begin{array}{l}002 \\
5\end{array}$ & $\begin{array}{r}0.0 \\
9\end{array}$ & & $\begin{array}{r}0.0 \\
7\end{array}$ & & & $\begin{array}{l}19 \\
9\end{array}$ & \\
\hline
\end{tabular}

* We report marginal effects for the probits. * $(\#, \triangle)$ denotes statistical significance at the 5\% (10\%, 1\%) level. 


\section{Appendix}

Table A1: The 2003 Corruptions Perceptions Index

\begin{tabular}{|c|c|c|}
\hline RANK & COUNTRY & SCORE \\
\hline 1. & Finland & 9.7 \\
\hline 2. & Iceland & 9.6 \\
\hline 3. & $\begin{array}{l}\text { Denmark } \\
\text { New Zealand }\end{array}$ & 9.5 \\
\hline 5. & Singapore & 9.4 \\
\hline m. & Netherlands & 8.9 \\
\hline 8. & Australia & 8.8 \\
\hline$\ldots$ & & \\
\hline 11. & United Kingdom & 8.7 \\
\hline$\ldots$ & & \\
\hline 18. & $\begin{array}{l}\text { Ireland } \\
\text { USA }\end{array}$ & 7.5 \\
\hline$\ldots$ & & \\
\hline 25. & Portugal & 6.6 \\
\hline$\ldots$ & & \\
\hline 35. & $\begin{array}{l}\text { Italy } \\
\text { Kuwait }\end{array}$ & 5.3 \\
\hline$\ldots$ & & \\
\hline 50. & $\begin{array}{l}\text { Costa Rica } \\
\text { Greece } \\
\text { South Korea }\end{array}$ & 4.3 \\
\hline$\ldots$ & & \\
\hline 83. & $\begin{array}{l}\text { India } \\
\text { Malawi } \\
\text { Romania }\end{array}$ & 2.8 \\
\hline 86. & $\begin{array}{l}\text { Russia } \\
\text { Mozambique }\end{array}$ & 2.7 \\
\hline$\ldots$ & & \\
\hline 122. & $\begin{array}{l}\text { Indonesia } \\
\text { Kenya }\end{array}$ & 1.9 \\
\hline 133. & Bangladesh & 1.3 \\
\hline
\end{tabular}

Source: Transparency International 


\section{University Library}

\section{- M M N E R VA A gateway to Melbourne's research publications}

Minerva Access is the Institutional Repository of The University of Melbourne

Author/s:

CAMERON, LISA;Chaudhuri, Ananish;ERKAL, NISVAN;GANGADHARAN, LATA

Title:

Do Attitudes Towards Corruption Differ Across Cultures?Experimental Evidence from Australia, India, Indonesia andSingapore

Date:

2005-07

Citation:

Cameron, Lisa and Chaudhuri, Ananish and Erkal, Nisvan and Gangadharan, Lata (2005) Do Attitudes Towards Corruption Differ Across Cultures?Experimental Evidence from Australia, India, Indonesia andSingapore.

Persistent Link:

http://hdl.handle.net/11343/34182 